Article

\title{
Information Disclosure, Coal Withdrawal and Carbon Emissions Reductions: A Policy Test Based on China's Environmental Information Disclosure
}

\author{
Nan Li, Beibei Shi * and Rong Kang \\ School of Economics and Management, Northwest University, Xi'an 710127, China; \\ lninshangbian@163.com (N.L.); kangrong@nwu.edu.cn (R.K.) \\ * Correspondence: shibeibei@nwu.edu.cn
}

Citation: Li, N.; Shi, B.; Kang, R. Information Disclosure, Coal

Withdrawal and Carbon Emissions Reductions: A Policy Test Based on China's Environmental Information Disclosure. Sustainability 2021, 13, 9758. https://doi.org/10.3390/ su13179758

Academic Editor: Jinsoo Kim

Received: 17 June 2021

Accepted: 27 August 2021

Published: 30 August 2021

Publisher's Note: MDPI stays neutral with regard to jurisdictional claims in published maps and institutional affiliations.

Copyright: (C) 2021 by the authors Licensee MDPI, Basel, Switzerland. This article is an open access article distributed under the terms and conditions of the Creative Commons Attribution (CC BY) license (https:/ / creativecommons.org/licenses/by/ $4.0 /)$.

\begin{abstract}
How to better explore a diversity of emissions reduction paths has become the key to China achieving carbon peak and carbon neutralization goals as well as transforming the existing energy structure as soon as possible. Based on this, from the perspective of information flow, this study used the differences-in-differences method (DID) to identify the "net effect" of the carbon emissions reduction caused by China's environmental information disclosure. The results showed the following: first, environmental information disclosure could effectively promote regional carbon emissions reductions and had a better effect on the central and western regions and low carbon emissions density regions. Second, the achievement of carbon emissions reduction targets was mainly attributed to the positive impact of information disclosure in the process of "coal withdrawal." Finally, this study also found that environmental information disclosure helped to promote the positive effect of clean energy development on "coal withdrawal," and the promotion of public awareness regarding environmental supervision helped to strengthen the external impact of environmental information disclosure on regional carbon emissions reduction.
\end{abstract}

Keywords: environmental information disclosure; coal withdrawal; coal efficiency; carbon emissions

\section{Introduction}

In the face of increasing global carbon emissions, addressing the challenge of climate change has become increasingly serious. The excessive increase in carbon emissions not only poses a threat to people's health, but also contributes to changes in urban microclimates [1,2]. As the largest developing country, China's carbon emissions have generally shown an upward trend since 1990, though the increasing rate of carbon emissions has slowed down since 2011. However, in terms of the total amount, China's emissions still account for a relatively high proportion of global carbon emissions (as shown in Figure 1). In April 2021, China's president, Xi Jinping, promised to achieve peak carbon dioxide emissions before 2030 and to achieve carbon neutrality by 2060 at the Leaders Summit on Climate. We can see that China has begun to promote carbon emissions reductions and determination from the top level. Therefore, exploring diversified ways to reduce carbon emissions reduction to realize China's carbon emissions reduction target is urgently needed.

Environmental information disclosure promotes the flow of information and data, which directly or indirectly affects a change in economic subject behavior, and thus has a "spillover" effect on the change in regional carbon emissions. Environmental information disclosure is different from the implementation of other policies for a single goal. By expanding information access channels, the amount of environmental information obtained by the whole society has increased, where regional government, enterprises, and the public have become the recipients of information disclosure, which provides the possibility for the government to strengthen environmental governance, adjust enterprise production behavior and to strengthen the public's environmental awareness. At the same time, environmental information disclosure adjusts the behavior of the whole society through the 
flow of information, which also provides all economic subjects with a buffer period to make decisions. Therefore, environmental information disclosure has certain practical significance. Regional carbon emissions are directly affected by energy consumption, especially coal consumption. In turn, the current situation of regional carbon emissions can indirectly reflect the current energy structure and its consumption in the target region. Therefore, the comprehensive evaluation and disclosure of the current regional environmental development situation are very important for the overall understanding of regional energy consumption and environmental quality. Furthermore, radiation provides strong support for the indirect information capture of regional carbon emissions statuses. While the disclosure of environmental information directly presents the real environmental status of the region as a form of external supervision, it also "forces" areas with weak environments to change their model of regional economic development and energy use, thus affecting a change in regional carbon emissions. Therefore, from the perspective of information flow, the research on the "spillover" impact of carbon emissions reduction that is brought about by environmental information disclosure is an important supplement to China's exploration of diversified ways to reduce carbon emissions.

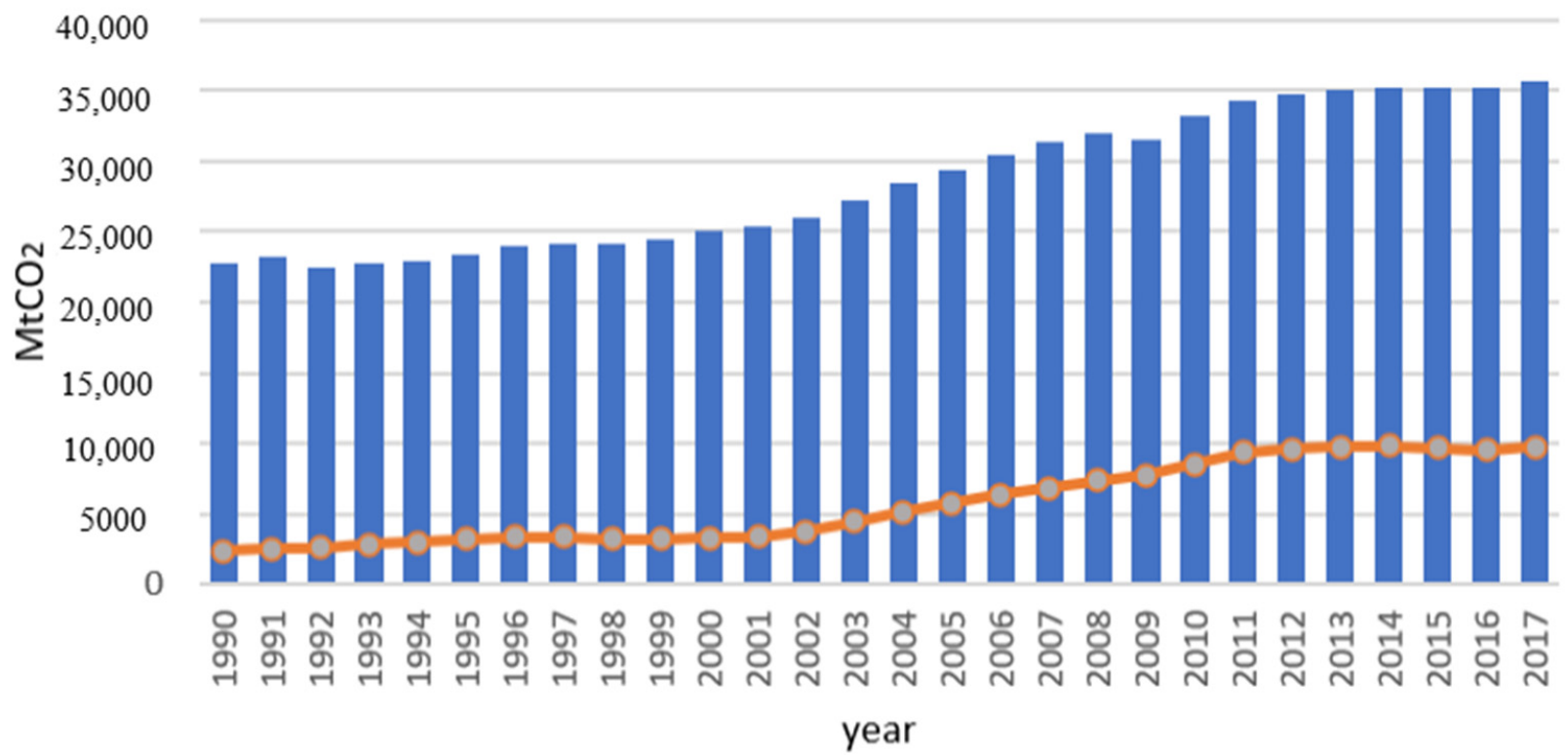

\section{World's carbon emissions $\quad$ China's total carbon emissions}

Figure 1. Carbon emissions situation of the world and China. Data source: Official website of the Global Carbon Atlas. (http:/ / www.globalcarbonatlas.org/cn/CO2-emissions, accessed on 15 May 2021).

In exploring diversified ways to reduce carbon emissions, changes in energy consumption, especially coal consumption, directly affect the emissions reduction results. Therefore, the impact of information disclosure on the change in coal consumption also indirectly determines the effect of regional carbon emissions reduction. A consideration of the impact of the change in energy consumption represented by coal is very important to reasonably evaluate the effectiveness of an information disclosure policy. In addition, taking coal as one of the focus centers also stems from China's current energy consumption reality. As a large coal-consuming country, China's coal consumption has shown an upward trend over the long term, and there is a phenomenon of spatial agglomeration. Consumption in the south and east of the country is higher than that in the north and west, respectively [3]. At the same time, it cannot be ignored that after the peak of China's coal consumption in 2013, there was a short decline from 2014 to 2015, but from the perspective of total coal consumption, China's coal consumption level is still at a high level [4]. 
The high proportion of coal in energy consumption also reflects how difficult it is to develop other energy consumption sources, especially renewable energy. The effective substitution of coal for renewable energy is the key to realizing "coal withdrawal" and promoting the reduction in carbon emissions. Therefore, society's attention toward the transformation of the existing energy structure and the recognition of the necessity to transform and develop renewable energy needs to be heightened. Promoting the transformation and development of energy is bound to require supporting policies that are related to energy, which involves the direct or indirect participation of many stakeholders [5]. The implementation of related policies is highly dependent on the environment. Therefore, it is necessary to integrate the views of relevant stakeholders into policy designs and to achieve a balanced effect in the process of promoting the implementation of energy policies, especially to improve citizens' participation in social energy transformation [6,7]. Environmental information disclosure involves a comprehensive presentation of the environmental situation in the region. Due to the disclosure and flow of information, this will first put pressure on the local government to strengthen environmental governance. As the regional manager and decision-maker, the government is bound to increase the restriction and supervision of the negative external environmental behavior that is brought about by regional enterprises. At the same time, having more transparent information also indirectly brings the public into the main body of environmental governance. In addition to strengthening external supervision, information disclosure provides the public with more choices regarding energy consumption. While promoting a change in public consumption behavior, it also promotes a change in the energy structure [8]. Based on this situation, whether environmental information disclosure can effectively promote the transformation of China's energy structure and achieve the goal of carbon emissions reduction is worthy of in-depth analysis.

Based on this background, this study aimed to explore whether the disclosure of environmental information helped to reduce China's carbon dioxide emissions. Did the implementation of this policy affect a change in carbon dioxide emissions by promoting China's "coal withdrawal" process? The relationship between the development of clean energy and the change in China's coal consumption, with the backdrop of environmental information disclosure, and the external impact of the improvement to public awareness of environmental supervision regards the change in carbon dioxide emissions caused by environmental information disclosure, are also the focus of this study.

Through this analysis, this study showed that environmental information disclosure could significantly reduce regional carbon emissions, where this result had a better impact on the central and western regions and low carbon emissions density regions. The reason for this result was that information disclosure could effectively promote China's "coal withdrawal" process, thus promoting the realization of carbon emissions reduction targets. At the same time, in terms of the transformation of the energy structure, environmental information disclosure could accelerate the substitution of clean energy for coal in China. In addition, the improvement of public awareness of environmental supervision also helped to strengthen the positive role of information disclosure in carbon emissions reduction.

At present, research into carbon emissions reduction methods mainly focuses on the improvement of the market mechanism and technological development. It is rarely explored at the government policy level, which is especially rooted in the information flow, an important resource in modern economic activities. Therefore, there is still a research gap regarding the exploration of ways to reduce carbon emissions based on the perspective of information disclosure. Based on this, the marginal contributions of this study include the following: (1) from the perspective of information flow, this study considered the carbon emissions reduction effect brought by environmental information disclosure, provided a research supplement to the exploration of carbon emissions reduction approaches from the perspective of information disclosure; and provided empirical support for the promotion of environmental information disclosure process and the scientific evaluation and improvement of relevant policies. (2) From the perspective of environmental information 
disclosure, this study used an internal logical test to determine the relationship between information disclosure and "coal withdrawal"; it further analyzed the transformation of China's energy structure; and supplemented the research on the impact of information on energy development, which is an important resource for current economic development. (3) Public environmental supervision was included in the research, the externality analysis of its impact on carbon emissions reduction caused by environmental information disclosure was carried out, research on the scope of the main body of environmental supervision was expanded; research support was provided regarding the necessity of paying attention to the cultivation of public environmental awareness and promoting the improvement of public participation in environmental protection.

\section{Literature Review}

In previous research, scholars mainly focused on two aspects in their research into the regional carbon emissions reduction path. On the one hand, taking the market mechanism as the research object, studies analyzed the design of the market mechanism and its carbon emission reduction effect, including the establishment of the carbon emissions trading market and the implementation of a carbon tax [9-15]. Many studies showed that the carbon-trading pilot could significantly reduce China's carbon emissions, but the efficiencies of the seven carbon pilot projects were generally low [16-20].

The pilot scheme in China's carbon emissions trading mainly focused on free quotas. For example, the allocation of carbon quotas in Beijing, Shanghai, and Guangdong was mainly based on the historical method, while the baseline method was introduced in Tianjin, Hubei, and Shenzhen [21]. However, for these two schemes, the baseline method needs detailed emissions data, while the historical method had only a few requirements regarding the amount of initial data. Therefore, in the early stage of the establishment of the carbon market, the distribution of the free historical method should be the main method $[22,23]$. As a typical example of the early implementation of the market mechanism to manage carbon emissions, the EU carried out dynamic reforms to the carbon emissions trading system [24-26]. Therefore, its market information operation efficiency was high [27]. In the initial stage of the EU-ETS, free quota allocation was also the main method, but great changes took place in the third stage of reform of the EU-ETS [28]. It was stipulated that the auction law will become the main carbon quota allocation method from 2013, and finally realize a complete auction method [29,30]. Similarly, Cong and Wei [31] stated that auctions under the ETS would gradually replace free distribution.

In terms of the impact effect, the carbon trading market in Hubei is considered to be an inefficient form [32]. Lin and Jia [33] conducted a more detailed study on the industries covered by China's carbon market. They found that the more the industries covered, the lower the carbon price, thus reducing the emissions reduction motivation of the enterprises that are covered. It is considered that only three industries, namely, the cement, chemical, and electric power industries, need to be covered to achieve the carbon emissions reduction target at a lower regulatory cost. Qu [34] studied the scale of the carbon trading market and found that the larger the market scale, the lower the global emissions reduction cost. Martin et al. [35] also carried out a series of analyses on the impact of the EU-ETS on enterprise carbon emissions. In addition, Li and Peng [36] found that a carbon tax helped to reduce carbon emissions and improved environmental quality, which was confirmed by many scholars $[37,38]$. Furthermore, some scholars analyzed the effect of a carbon tax on carbon emissions reductions under specific conditions [39,40].

However, research on the carbon emissions reduction path focused on the technical level, such as CCUS (Carbon Capture Utilization and Storage) [41,42]; and other lowcarbon technology innovations $[43,44]$. Chen et al. [45] studied the potential role of CCS in China's carbon emissions reduction in 2050 and found that CCS could reduce the marginal emissions reduction cost and that the emissions reduction rate could reach $45 \%$. Craig et al. [46] compared the carbon emissions reduction results of flexible CCS and conventional CCS and found that flexible CCS was an economic carbon emissions reduction 
strategy. However, at the same time, it cannot be ignored that compared with other clean energy technologies, the Chinese public still has a low understanding of CCS [47]. It can be considered that carbon capture, utilization, and storage (CCUS) technology will likely become an important approach for reducing carbon dioxide $\left(\mathrm{CO}_{2}\right)$ emissions and optimizing the structure of energy consumption in China in the future [48]. Zhou and $\mathrm{Li}$ [49] analyzed the impact of technological innovation diffusion on carbon emissions based on the theory of a low-carbon economy and technological innovation diffusion; and found that the key to achieving the carbon emissions reduction goal is to improve the carbon emissions effect level regarding the diffusion of technological innovation's carbon productivity (the reciprocal of carbon emissions intensity per unit GDP). Subsequently, the development of low-carbon technology plays an important role in carbon emissions reduction, which was also supported by other scholars $[50,51]$.

In addition, regarding environmental information disclosure, recent research mainly focused on air and water pollution. Feng [52] discussed the impact of environmental information disclosure on air pollution and economic development; and found that air pollution hindered economic development, while the disclosure of environmental information effectively reduced the situation of underreporting pollution; thus that the environmental report published by the government can more accurately reflect the air quality. Lin [53] studied the relationship between air pollution and environmental information disclosure from the perspective of industry; and found that there was a significant negative correlation between air pollution and environmental information disclosure by enterprises, where the effect of this was greater in the eastern region. Zhong [54] took sulfur dioxide as a research object and found that environmental information disclosure was significantly conducive to reducing sulfur dioxide emissions in the region; and that environmental information disclosure had a significant positive spatial spillover effect. The improvement in the environmental information transparency index of surrounding cities helped to improve the $\mathrm{SO} 2$ removal rate of local cities. It can be seen that the implementation of information disclosure can effectively control pollution [55].

For the governance of water pollution, studies showed that environmental information disclosure had a strong role in promoting the governance of water pollution [56]. However, due to the increasingly wide application of water pollution prevention and control, the existing problems of water environmental information disclosure also attracted some attention, including the lack of a standardized water environment information disclosure, the poor implementation of enterprise emissions information disclosure, the unbalanced information supply and demand [57]; and the weak service function of the water environment data platform [58]. From the perspective of the government, government agencies play a dominant role in information disclosure, but they do not play an ideal role in information disclosure, which could result in potential resistance to the promotion of water pollution information disclosure [59].

Through a literature review, it was found that the current discussion on the path of carbon emissions reduction mainly focused on the improvement of the market mechanism and the development of technology. There is still a gap in the research on the effect of carbon emissions reduction at the policy level, especially from the perspective of information disclosure. By further exploring the impact of environmental information disclosure policies, it was found that it mainly involves air and water pollution, which further confirms that there is a lack of impactful research on the implementation of policy that focuses on the effect of carbon emissions reduction. Based on this, from the perspective of information flow, this study identified the causality of carbon emissions reduction caused by the implementation of environmental information disclosure policies and aimed to explore the effectiveness of carbon reduction approaches from the perspective of information disclosure and scientifically evaluate the implementation of environmental information disclosure policies.

The remainder of this paper is arranged as follows: Section 3 presents a theoretical mechanism analysis. Section 4 presents the research design. Section 5 presents the bench- 
mark regression results. Section 6 presents the impact mechanism test. Section 7 presents further discussions, and finally, conclusions are drawn in Section 8.

\section{Theoretical Mechanism Analysis}

The implementation of environmental information disclosure makes the environmental situation of the involved areas open. Due to the disclosure being in a quantitative form, it provides the possibility for a horizontal comparison of environmental quality between the regions and the further acquisition of environmental quality information of the region by the public. For local governments, through the comparison of scores, officials in areas with lower environmental scores are faced with greater pressure from political promotion and environmental assessments. The improvement to regional environmental quality helps to improve the promotion probability of officials [60]. Thus, under the environmental assessment, local officials will compete with local government officials at the same level regarding environmental protection to obtain promotion opportunities [61]. Under this background, officials in areas with higher environmental scores will obtain more promotion advantages, while the promotion pressure of officials in areas with lower environmental scores will increase. At the same time, the latter is more likely to attract the attention of environmental protection departments because of the low performance of environmental quality assessment, which will strengthen environmental supervision and make it a key supervision object.

From the public's point of view, the implementation of environmental information disclosure expands the amount of information that is related to regional environmental quality; and further stimulates the public's participation in environmental protection. The improvement to public participation helps to improve the government's environmental decision-making [62]. In the areas with low environmental scores, for the public who grasp the situation, it will increase the demand for an improvement in environmental quality, which will form strong external pressure on the government to strengthen regional environmental governance. Under the combined effect of the above two factors, the local government will make every effort to improve regional environmental quality, strengthen regional environmental governance and supervision, and strive to reverse the poor environmental situation in the region. This behavior is conducive to promoting the reduction in carbon dioxide emissions in the region.

Furthermore, due to the relatively backward technology level, the central and western regions are more inclined to sacrifice the environment for economic development, and the environmental information disclosure exposes the fragile environmental situation of the central and western regions, thus making them the key governance and regulatory objects. Therefore, compared to the eastern region, the promotion of environmental information disclosure in the central and western regions brings about a better carbon emissions reduction effect. Meanwhile, regions with higher carbon emissions densities require a higher degree of industrial development and upgrading their industrial structures such that they are arranged and promoted from an overall perspective. Therefore, compared to the operability of regions with lower carbon emissions densities, the effect of environmental information disclosure of carbon emissions reduction is weaker in regions with higher carbon emissions densities.

Hypothesis 1. Environmental information disclosure helps to reduce regional carbon dioxide emissions, where this effect differs due to different regional factor endowments and carbon emissions densities.

At present, the level of coal consumption in China is very high, and the large amount of fossil fuel energy use that is represented by coal is the main reason for the increase in regional carbon dioxide emissions [63]. Thus, "coal control" is the fundamental way to achieve the regional carbon emissions reduction goal. The publication of the pollution source regulatory information disclosure index (PITI) in China is based on the actual discharge of industrial COD and sulfur dioxide emissions in each city. This is found 
by calculating the amount of information that should be disclosed. Based on this, the systematic evaluation of information disclosure in each region is carried out. It can be seen that the amount of sulfur dioxide emissions in each region is one of the factors that directly affect the evaluation results. Coal is an important factor that affects the emissions of sulfur dioxide. Improving the quality of coal and reducing terminal emissions have become the main ways to restrict the emissions of sulfur dioxide [64]. Therefore, under the backdrop of environmental information disclosure, the government is bound to focus on coal and reduce the emissions of sulfur dioxide by restricting regional coal consumption to promoting an improvement in regional environmental score.

The consumption of industrial coal accounts for a large proportion of the entire social coal consumption. Therefore, the government's promotion of the "coal control" process will inevitably focus on the key areas of industry, restrict the overall consumption by regional industries, reduce the dependence of industrial development on coal, and promote the gradual realization of "coal withdrawal" in the region. In addition, coal is the key energy source that is used to support economic development. To reduce the impact of restricting coal consumption on economic development, local development will pay more attention to improving the utilization efficiency of coal, release the technological dividend caused by technological innovation regarding energy use to the greatest extent, and balance the relationship between social development and environmental protection by saving the use of coal.

Hypothesis 2. Environmental information disclosure achieves regional carbon emissions reduction targets by promoting the reduction of industrial coal consumption and the improvement of coal utilization efficiency.

In China, coal is currently the most important energy source for production and life. The promotion of "coal withdrawal" will have a great impact on the operation of the whole society. With this backdrop, the key way to solve this problem is to find other energy sources to replace coal effectively. In the process of "coal withdrawal," the government will favor clean energy first. Clean energy can not only provide an energy supply for production and life but can also have the advantage of low carbon emissions. From the perspective of sustainable development, the long-term lack of a reliable supply of clean energy will become an obstacle to regional development [65]. Therefore, environmental information disclosure will enable local governments to increase financial subsidies and preferential policy support for clean energy, which will give clean energy a certain competitive advantage in terms of price, thus that it can occupy a favorable position in the competition with coal consumption.

In addition, public participation in environmental protection represented by environmental letters has a positive effect on the improvement of regional environmental quality [66]. The improvement in the public awareness of environmental supervision means that it is more sensitive to regional environmental information. The background of environmental information disclosure will increase the requirements for regional environmental protection and will "force" the government to expand the governance of the environment. Thus, the improvement of public awareness of environmental supervision helps to strengthen the effect of carbon emissions reduction caused by environmental information disclosure.

Hypothesis 3. With the background of environmental information disclosure, the development of regional clean energy is conducive to promoting the process of "coal withdrawal," and the improvement in the public awareness of environmental supervision helps to strengthen the effect of carbon emission reduction caused by information disclosure. 


\section{Research Design}

\subsection{Model Building and Research Procedure}

To identify the "net effect" of environmental information disclosure on regional carbon emissions reduction, this study constructed a differences-in-differences (DID) model for the analysis. For carbon emissions, this study mainly identified the impact results from the micro prefecture-level city and the macro provincial level. Limited by data acquisition, for prefecture-level cities, this study selected the data from 2003 to 2018 . For the provincial level, this study updated the data to the latest data from 2019. The DID method is usually used to evaluate the effect of policy implementation. This method mainly extracts the "net effect" of the impact of the policy on the treatment group through the two differences between the policy implementation effect of the treatment group and the control group. Specifically, the first difference is the difference (or elimination) of the impact results caused by the natural development trend of the treatment group. On this basis, the second difference is the treatment affected by the policy and the development of the control group that is not affected by the policy to identify the policy impact. In other words, the policy effect can be identified by comparing the difference between the intervention group that is affected by the policy and the control group, which is not affected [67]. The DID method was selected because of its unique advantage. This method can effectively eliminate endogenous problems and eliminate the impact of other policies on regional carbon emissions reduction to identify the "net effect" of the implementation of the environmental information disclosure policy on carbon emissions [68]. Therefore, the impartiality and effectiveness of the research results can be improved. The specific Equation (1) was constructed as follows:

$$
\text { carbonemission }_{i t}=\alpha_{0}+\alpha_{1} \text { EIO }_{i t}+\sum \text { Control }_{i t}+\mu_{i}+\pi_{t}+\varepsilon_{i t}
$$

In Equation (1), carbonemission $_{i t}$ refers to the carbon emissions of region $i$ in year $t$, which were measured in terms of the regional total carbon emissions $\left(\right.$ totalCO $\left.\mathrm{CO}_{2}\right)$, carbon

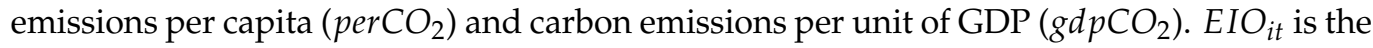
environmental information disclosure status of region $i$ in year $t$. If it is the disclosed city, the value is 1 ; otherwise it is 0 . Control $i$ represents a series of control variables that affect regional carbon emissions, including the economic agglomeration (ag), GDP per capita $($ pergdp), GDP per capita square (pergdp2), investment in industrial pollution governance (polluteinvest), total foreign direct investment (fdi), degree of openness to the outside world (open) and green coverage area (green). $\mu_{i}$ and $\pi_{t}$ denote the fixed urban and time effects, respectively. $\varepsilon_{i t}$ is the stochastic disturbance term. $\alpha_{1}$ is our major concern here.

In addition, to make the research results more logical, this paper presents the subsequent research procedure in the form of a diagram. The specific results are shown in Figure 2.

\subsection{Index Selection}

The following were the explained variables in this study: regional total carbon emissions, carbon emissions per capita, and carbon emissions per unit of GDP. In reference to the calculation method developed by Han and Xie [69] for carbon dioxide emissions for prefecture-level cities, this study calculated the carbon emissions of the industrial consumption of natural gas, liquefied petroleum gas, and industrial coal-fired electricity and summed up the above three results. The specific calculation equation was as follows:

$$
\text { total } \mathrm{CO}_{2}=g a s \mathrm{CO}_{2}+\text { oilCO } \mathrm{CO}_{2}+\text { electricity } \mathrm{CO}_{2}=\vartheta \times g a s+\tau \times \text { oil }+\omega \times(\varphi \times \text { totalelectricity })
$$




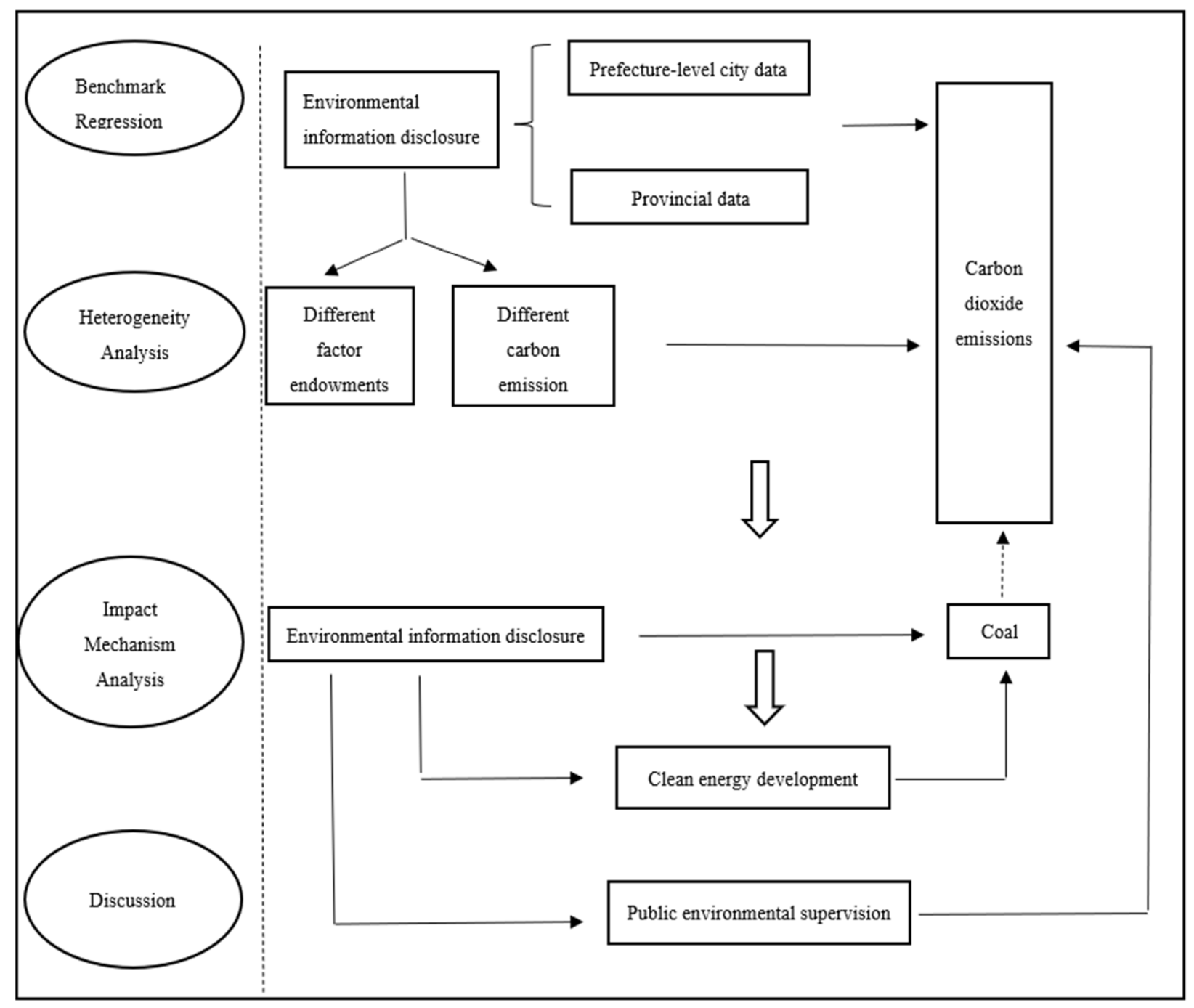

Figure 2. Research procedure.

In Equation (2), totalCO $\mathrm{CO}_{2}$ is the total carbon emissions. gasCO $\mathrm{CoilCO}_{2}$, and electricity $\mathrm{CO}_{2}$ represent the carbon emissions from the industrial consumption of natural gas, liquefied petroleum gas, and industrial coal-fired electricity, respectively. $\vartheta$ is the carbon emissions coefficient of natural gas. $\tau$ is the carbon emissions coefficient of liquefied petroleum gas. gas and oil represent industrial gas consumption and liquefied petroleum gas consumption, respectively. $\omega$ is the greenhouse gas emissions coefficient of the coal electricity fuel chain. $\varphi$ represents the proportion of coal-fired electricity generation in the total electricity generation. totalelectricity is the industrial electricity consumption. Based on this, the total carbon emissions from each prefecture-level city were calculated using data from 2003 to 2018. Then, from the perspective of population and economic development, the carbon emissions per capita and carbon emissions per unit of GDP were calculated.

In addition, in the process of calculating the carbon emissions of each prefecture-level city, the coal consumption for industrial power was used as one of the accounting indicators, and part of the coal consumption of power was not used for power generation. Therefore, the calculation of the carbon emissions of prefecture-level cities may be overestimated. Meanwhile, since the relevant data from prefecture-level cities were only available from 2003 to 2018, to ensure the robustness of the research results, this study further calculated the provincial carbon emissions and advanced the calculation time of carbon emissions to 2019, which used the latest updated data. The calculation of the provincial carbon emissions was mainly based on the consumption of coal, oil, and natural gas in each 
province. This study adopted the international general calculation method, that is, the energy consumption was multiplied by the carbon emissions coefficient to obtain the energy carbon emissions. On this basis, the amount of total regional carbon emissions was obtained by summing up all energy carbon emissions.

Explanatory variable. The implementation of an environmental information disclosure policy was regarded as the explanatory variable in this study. This was based on the pollution source regulatory information disclosure indexes (PITIs) of 113 cities in China, which were jointly disclosed by the institute of public and environmental affairs (IPE) and the American Natural Resources Defense Council (NRDC) in 2008. This study took this behavior as a quasi-natural experiment to identify the causal relationship between it and the regional carbon emissions. Specifically, for the cities with environmental information disclosure after 2008, the value was 1 ; otherwise it was 0 . When using the PITI for the evaluation, the relevant expert team calculated the coefficient evaluation score based on the regional industrial COD and sulfur dioxide emissions.

Control variables. For the other variables that may affect regional carbon emissions, this study added and controlled them in the model from the perspectives of economic development and environmental protection. From the perspective of economic development, referring to the variable selection by Shi [70], this study took total foreign direct investment as a control variable in the model. In addition, this study further added the economic agglomeration degree, GDP per capita, investment in industrial pollution governance, and the degree of openness to the outside world as control variables. In addition, because there may be an EKC (environmental Kuznets curve) relationship between air pollution, which is dominated by carbon emissions and economic growth [71-74], the square of the GDP per capita was also added to the model as a control variable. From the perspective of the development of environmental protection, we believed that the green coverage area would also have a certain impact on regional carbon emissions; therefore, this variable was also included as a control variable.

\subsection{Data Sources}

The data used in this paper came from the China City Statistical Yearbook, the China Electric Power Yearbook, the China Statistical Yearbook, the China Environment Yearbook, provincial government websites, and the Wind database. In this study, all the variables involved were analyzed using descriptive statistics. It can be seen that the values of all the variables were in a reasonable range, which shows that the variables selected in this study were effective. The specific results are shown in Table 1.

Table 1. Descriptive statistical analysis of major variables.

\begin{tabular}{|c|c|c|c|c|}
\hline Variable & Variable Meaning & Computing Method & Mean & SD \\
\hline totalCO $\mathrm{CO}_{2}$ & total carbon emissions & logarithm of total carbon emissions & 14.7459 & 1.5458 \\
\hline perCO$_{2}$ & carbon emissions per capita & $\begin{array}{l}\text { logarithm of (total carbon } \\
\text { emissions/total regional population) }\end{array}$ & 8.8929 & 1.5379 \\
\hline $\operatorname{gdpCO}_{2}$ & carbon emissions per unit of GDP & $\begin{array}{l}\text { logarithm of (total carbon } \\
\text { emissions / regional GDP) }\end{array}$ & 8.0010 & 1.1816 \\
\hline $\mathrm{EIO}$ & environmental information disclosure & $\begin{array}{l}\text { virtual variable, the city of } \\
\text { environmental information disclosure } \\
\text { is } 1 \text {, otherwise it is } 0\end{array}$ & 0.2692 & 0.4436 \\
\hline ag & economic agglomeration & $\begin{array}{c}\text { total output value of } \\
\text { non-agricultural/land area }\end{array}$ & 0.1884 & 0.5134 \\
\hline pergdp & GDP per capita & $\begin{array}{l}\text { regional GDP/total } \\
\text { regional population }\end{array}$ & 3.9205 & 4.5671 \\
\hline pergdp2 & square of the GDP per capita & GDP per capita GDP per capita & 36.2253 & 136.3878 \\
\hline polluteinvest & $\begin{array}{l}\text { investment in industrial } \\
\text { pollution governance }\end{array}$ & $\begin{array}{l}\text { total investment in industrial } \\
\text { pollution governance }\end{array}$ & 23.3919 & 21.0771 \\
\hline
\end{tabular}


Table 1. Cont.

\begin{tabular}{|c|c|c|c|c|}
\hline Variable & Variable Meaning & Computing Method & Mean & SD \\
\hline fdi & total foreign direct investment & $\begin{array}{l}\text { logarithm of total foreign } \\
\text { direct investment }\end{array}$ & 2.3716 & 1.9478 \\
\hline open & $\begin{array}{l}\text { degree of opening to the } \\
\text { outside world }\end{array}$ & share of (export/import) & 1.5446 & 1.4414 \\
\hline green & green coverage area & total green coverage area & 0.4944 & 0.8660 \\
\hline percoal & industrial coal consumption per capita & $\begin{array}{l}\text { logarithm of (industrial coal } \\
\text { consumption/total } \\
\text { regional population) }\end{array}$ & 9.7200 & 0.7174 \\
\hline gdpcoal & $\begin{array}{l}\text { industrial coal consumption per unit } \\
\text { of GDP }\end{array}$ & $\begin{array}{l}\text { logarithm of (industrial coal } \\
\text { consumption/GDP) }\end{array}$ & 8.8059 & 0.4221 \\
\hline gas & natural gas consumption & total natural gas consumption & 50.8447 & 54.3079 \\
\hline gasinfrastructure & total investment in gas infrastructure & $\begin{array}{l}\text { total government investment in } \\
\text { gas infrastructure }\end{array}$ & 12.0413 & 12.8715 \\
\hline letter & $\begin{array}{l}\text { degree of public environmental } \\
\text { supervision }\end{array}$ & $\begin{array}{l}\text { proportion of the number of handling } \\
\text { letters in total number of letters }\end{array}$ & 1.0090 & 0.2281 \\
\hline
\end{tabular}

\section{Results}

5.1. Impact of Environmental Information Disclosure on Regional Carbon Dioxide Emissions and Its Difference Analysis: DID Test

Based on the theoretical analysis, this study analyzed the impact of environmental information disclosure on the realization of regional carbon emissions reduction targets from an empirical perspective. Columns (1-3) represent the test results from the prefecturelevel cities, and columns (4-6) represent the test results at the provincial level. The specific results are shown in Table 2. Columns (1) and (4) represent the impact of environmental information disclosure on regional carbon dioxide emissions. It can be seen that the disclosure of environmental information was conducive to promoting a reduction in regional carbon emissions, where these results passed the $1 \%$ and $10 \%$ significance level tests, respectively. As carbon emissions are closely related to the population and the economic development of a region, the change in total carbon emissions cannot objectively reflect a region's carbon reduction effect. Therefore, this study conducted a more in-depth analysis of the impact of environmental information disclosure on the carbon emissions reduction from the perspective of carbon emissions per capita and carbon emissions per unit of GDP. The specific results are shown in columns (2), (3), (5) and (6). It can be seen that the disclosure of environmental information also significantly reduced the carbon emissions per capita and carbon emissions per unit of GDP, especially for the prefecturelevel cities. To sum up, the disclosure of environmental information did help to reduce regional carbon dioxide emissions.

Table 2. Impact of environmental information disclosure on regional carbon dioxide emissions.

\begin{tabular}{|c|c|c|c|c|c|c|}
\hline & totalCO $\mathrm{CO}_{2}$ & perCO $_{2}$ & $\mathrm{gdpCO}_{2}$ & totalCO $\mathrm{CO}_{2}$ & perCO $_{2}$ & $\operatorname{gdpCO}_{2}$ \\
\hline & $\begin{array}{c}\text { City } \\
\text { (1) }\end{array}$ & $\begin{array}{l}\text { City } \\
\text { (2) }\end{array}$ & $\begin{array}{l}\text { City } \\
\text { (3) }\end{array}$ & $\begin{array}{l}\text { Province } \\
\text { (4) }\end{array}$ & $\begin{array}{l}\text { Province } \\
\text { (5) }\end{array}$ & $\begin{array}{c}\text { Province } \\
\text { (6) }\end{array}$ \\
\hline EIO & $\begin{array}{c}-0.2146^{* * *} \\
(0.0475)\end{array}$ & $\begin{array}{c}-0.2329^{* * *} \\
(0.0501)\end{array}$ & $\begin{array}{c}-0.1080 \text { ** } \\
(0.0493)\end{array}$ & $\begin{array}{c}-0.0212 * \\
(0.0114)\end{array}$ & $\begin{array}{c}-0.0250 * * \\
(0.0112)\end{array}$ & $\begin{array}{l}-0.0323 \\
(0.0446)\end{array}$ \\
\hline $\begin{array}{l}\text { Control } \\
\text { variable }\end{array}$ & Yes & Yes & Yes & Yes & Yes & Yes \\
\hline Year fixed effect & Yes & Yes & Yes & Yes & Yes & Yes \\
\hline $\begin{array}{l}\text { Region fixed } \\
\text { effect }\end{array}$ & Yes & Yes & Yes & Yes & Yes & Yes \\
\hline _cons & $\begin{array}{c}18.0673^{* * *} \\
(0.2963)\end{array}$ & $\begin{array}{c}10.9499 * * * \\
(0.3063)\end{array}$ & $\begin{array}{c}9.4771^{* * *} \\
(0.4891)\end{array}$ & $\begin{array}{c}16.9662 * * * \\
(0.0871)\end{array}$ & $\begin{array}{c}9.4784^{* * *} \\
(0.1102)\end{array}$ & $\begin{array}{c}6.8181^{* * *} \\
(0.1683)\end{array}$ \\
\hline $\mathrm{N}$ & 4270 & 4270 & 4270 & 3984 & 3984 & 4276 \\
\hline $\mathrm{r} 2$ & 0.8025 & 0.8001 & 0.6145 & 0.9065 & 0.8648 & 0.3372 \\
\hline
\end{tabular}

Note: ${ }^{*}, * *, * *$ are significant at the level of $10 \%, 5 \%$ and $1 \%$, respectively; In parentheses is the value of robust standard error. 
There were some differences between the prefecture-level city and provincial data results, mainly due to the following two reasons: first, the calculation used for prefecturelevel city carbon emissions data may have been overestimated, resulting in a greater impact of environmental information disclosure regarding prefecture-level city carbon emissions reduction. Second, prefecture-level city-data belonged to the set of micro-data, while provincial data belonged to the set of macro-data, where micro-data involved more comprehensive and detailed information at the statistical level. Therefore, compared with the regression results for these two data levels, the prefecture-level city level could reflect more information.

The reason for this result may be that environmental information disclosure could present the real environmental situation through a comprehensive scoring of the regional environment, and this form was conducive to promoting the horizontal comparison of the environmental status of various regions. For local government officials who face a low comprehensive regional environment score, the pressure from environmental assessment and political promotion will become greater. In this context, they will strengthen the governance of the regional environment, which will help to promote the improvement of the regional environmental quality.

\subsection{Heterogeneity Analysis}

Heterogeneity analysis under different factor endowments: due to the different development bases between different regions in China, the development results were quite different. For example, the eastern region had a higher level of economic development, a relatively complete infrastructure, a dense population, and a higher level of openness to the outside world, while the central and western regions were relatively weak in all aspects. Therefore, the carbon emission reduction effect of environmental information disclosure under different factor endowments could be quite different. Based on this analysis, this study divided China into an eastern region (east) and central and western regions (central and western). It analyzed the heterogeneity of the carbon emissions reduction effect that was caused by environmental information disclosure from the perspective of these two regions. The specific results are shown in Table 3.

Table 3. Difference analysis of the impact of environmental information disclosure on regional carbon dioxide emissions under different factor endowments.

\begin{tabular}{|c|c|c|c|c|c|c|}
\hline & totalCO $\mathrm{CO}_{2}$ & totalCO $\mathrm{CO}_{2}$ & perCO $_{2}$ & perCO $_{2}$ & $\operatorname{gdpCO}_{2}$ & $\operatorname{gdpCO}_{2}$ \\
\hline & (1) & (2) & (3) & (4) & (5) & (6) \\
\hline $\mathrm{EIO}^{*}$ east & $\begin{array}{c}-0.1847 \text { ** } \\
(0.0643)\end{array}$ & & $\begin{array}{c}-0.1891 \text { ** } \\
(0.0662)\end{array}$ & & $\begin{array}{l}-0.0317 \\
(0.0629)\end{array}$ & \\
\hline \multirow[t]{2}{*}{$\begin{array}{l}\mathrm{EIO}{ }^{*} \text { central } \\
\text { and western }\end{array}$} & & $-0.2463^{* *}$ & & $-0.2708^{* * *}$ & & -0.1551 \\
\hline & & $(0.0832)$ & & $(0.0864)$ & & $(0.0920)$ \\
\hline $\begin{array}{l}\text { Control } \\
\text { variable }\end{array}$ & Yes & Yes & Yes & Yes & Yes & Yes \\
\hline \multirow{3}{*}{$\begin{array}{c}\text { Year fixed effect } \\
\text { Region fixed } \\
\text { effect } \\
\text { _cons }\end{array}$} & Yes & Yes & Yes & Yes & Yes & Yes \\
\hline & Yes & Yes & Yes & Yes & Yes & Yes \\
\hline & $\begin{array}{c}18.1331 * * * \\
(0.1831)\end{array}$ & $\begin{array}{c}16.8850 * * * \\
(0.2699)\end{array}$ & $\begin{array}{c}10.9488^{* * *} \\
(0.1934)\end{array}$ & $\begin{array}{c}11.0703^{* * *} \\
(0.2752)\end{array}$ & $\begin{array}{c}9.4112 * * * \\
(0.2856)\end{array}$ & $\begin{array}{c}10.2201^{* * *} \\
(0.4280)\end{array}$ \\
\hline $\mathrm{N}$ & 1865 & 2405 & 1865 & 2405 & 1865 & 2405 \\
\hline r2 & 0.7865 & 0.7990 & 0.7462 & 0.8245 & 0.4944 & 0.6974 \\
\hline
\end{tabular}

Note: ${ }^{*} * * * * *$ are significant at the level of $10 \%, 5 \%$ and $1 \%$, respectively; In parentheses is the value of robust standard error.

It can be seen that whether the total carbon emissions, carbon emissions per capita, or carbon emissions per unit of GDP were considered, the environmental information disclosure in the central and western regions had a better effect on regional carbon emission reduction, and the total carbon emissions results passed the 5\% significance level test, 
carbon emissions per capita results passed the $1 \%$ significance level test, that is to say, the range of the carbon emissions reduction is greater. While the environmental information disclosure in the eastern region also had a positive effect on the carbon emissions reduction, the emissions reduction range was still relatively small.

The reason for this result may have been that the economic development of the central and western regions was relatively slow, and their technological innovation ability and energy utilization efficiency lagged behind those of the eastern region. Therefore, the central and western regions were more inclined to promote economic growth through the extensive economic development model of sacrificing the environment for economic development. The promotion of environmental information disclosure exposed the fragile environmental foundation of the central and western regions, which was conducive to "forcing" the regions to carry out environmental governance with greater intensity. Therefore, compared with the eastern region, the effect of environmental information disclosure on carbon emissions reduction in the central and western regions was better.

Heterogeneity analysis under different carbon emissions densities: under the background of different carbon emissions densities, the impact of environmental information disclosure on regional carbon emissions reduction was also different. Based on this, this study took carbon emissions per capita as a measurement index, sorted the mean value of each province's carbon emissions per capita, and divided it into two categories to distinguish the regional carbon emissions density. The specific results are shown in Table 4.

Table 4. Difference analysis of the impact of environmental information disclosure on regional carbon dioxide emissions under different carbon emissions densities.

\begin{tabular}{|c|c|c|c|c|c|c|}
\hline & totalCO $\mathrm{CO}_{2}$ & totalCO $\mathrm{CO}_{2}$ & perCO $_{2}$ & perCO $_{2}$ & $\mathrm{gdpCO}_{2}$ & $\operatorname{gdpCO}_{2}$ \\
\hline & (1) & (2) & (3) & (4) & (5) & (6) \\
\hline $\mathrm{EIO}^{*}$ low & $\begin{array}{c}-0.3057^{* * *} \\
(0.0787)\end{array}$ & & $\begin{array}{c}-0.3249^{* * *} \\
(0.0807)\end{array}$ & & $\begin{array}{c}-0.2010^{* *} \\
(0.0771)\end{array}$ & \\
\hline $\mathrm{EIO} *$ high & & $\begin{array}{l}-0.0956 \\
(0.1781)\end{array}$ & & $\begin{array}{l}-0.1077 \\
(0.0618)\end{array}$ & & $\begin{array}{c}0.0296 \\
(0.0649)\end{array}$ \\
\hline $\begin{array}{l}\text { Control } \\
\text { variable }\end{array}$ & Yes & Yes & Yes & Yes & Yes & Yes \\
\hline Year fixed effect & Yes & Yes & Yes & Yes & Yes & Yes \\
\hline $\begin{array}{l}\text { Region fixed } \\
\text { effect }\end{array}$ & Yes & Yes & Yes & Yes & Yes & Yes \\
\hline _cons & $\begin{array}{c}16.3306^{* * *} \\
(0.3048)\end{array}$ & $\begin{array}{c}18.0063^{* * *} \\
(0.2116)\end{array}$ & $\begin{array}{c}9.5245^{* * *} \\
(0.3247)\end{array}$ & $\begin{array}{c}10.8418^{* * *} \\
(0.2132)\end{array}$ & $\begin{array}{c}9.0435^{* * *} \\
(0.4640)\end{array}$ & $\begin{array}{c}9.3595^{* * *} \\
(0.3879)\end{array}$ \\
\hline $\mathrm{N}$ & 2489 & 1781 & 2489 & 1781 & 2489 & 1781 \\
\hline r2 & 0.7597 & 0.8218 & 0.7583 & 0.8077 & 0.6127 & 0.6118 \\
\hline
\end{tabular}

Note: ${ }^{* * *},{ }^{* *}$ are significant at the level of $10 \%, 5 \%$ and $1 \%$, respectively; In parentheses is the value of robust standard error.

It can be seen that whether the total carbon emissions, carbon emissions per capita, or carbon emissions per unit of GDP were considered, the effect of environmental information disclosure on the carbon emissions reduction was better in low carbon emissions density areas, and the results of total carbon emissions and carbon emissions per capita passed the $1 \%$ significance level test, the results of carbon emissions per unit GDP passed the 5\% significance level test. Environmental information disclosure had a positive impact on carbon emissions reduction in high carbon emissions density areas, but the results were not significant.

Areas with high carbon emissions densities meant that the industrial economy developed rapidly, and the economic agglomeration ability was strong. The basic level of carbon emissions in these areas was high. Therefore, the impact of external constraints that were caused by environmental information disclosure on carbon emissions reduction could only be highlighted through the long-term effect. For low carbon emissions density areas, the impact of external environmental constraints could better transform the regional development model and quickly reverse the regional environmental quality. Therefore, 
compared to the former, the effect of the carbon emissions reduction caused by environmental information disclosure in low carbon emissions density areas was better. At the same time, it should be noted that the areas with a high carbon emissions density should become the key targets of carbon emissions reductions under environmental information disclosure, but this result is not ideal. Therefore, the impact of external environmental constraints on these areas may need to be improved regarding the intensity and manner of constraints. Hypothesis 1 was, therefore, verified.

\section{Research on the Relationship between Environmental Information Disclosure and Coal Withdrawal}

As the main source of carbon dioxide emissions, coal consumption directly affects the realization of a carbon emissions reduction target. The promotion of the "coal withdrawal" process can reduce the use of fossil fuel energy and promote the transformation of the energy structure in the region to promote the realization of carbon-neutral and sustainable development in the region as soon as possible. Thus, reducing coal consumption as much as possible is the most effective way to quickly achieve regional carbon emissions reduction goals.

At present, the consumption of coal in relation to China's total energy consumption is still large. As can be seen from Figure 3, China's coal consumption showed a rapid upward trend after 2000. There was a short-term decline after 2013. However, from the perspective of total consumption, compared to other countries in the world, China's coal consumption is still in a higher position. It can be seen that there is a long way to go to promote the process of "coal withdrawal" for China. Through the benchmark regression results, we can see that the environmental information disclosure was significantly conducive to the reduction in regional carbon dioxide emissions. Meanwhile, according to the theoretical analysis, environmental information disclosure increased the impact of local governments' regional coal consumption. With the background of environmental information disclosure, whether the government's influence in regional coal use was conducive to reducing coal consumption and improving coal utilization efficiency, thus promoting the realization of carbon emission reduction goals, was worthy of further in-depth analysis.

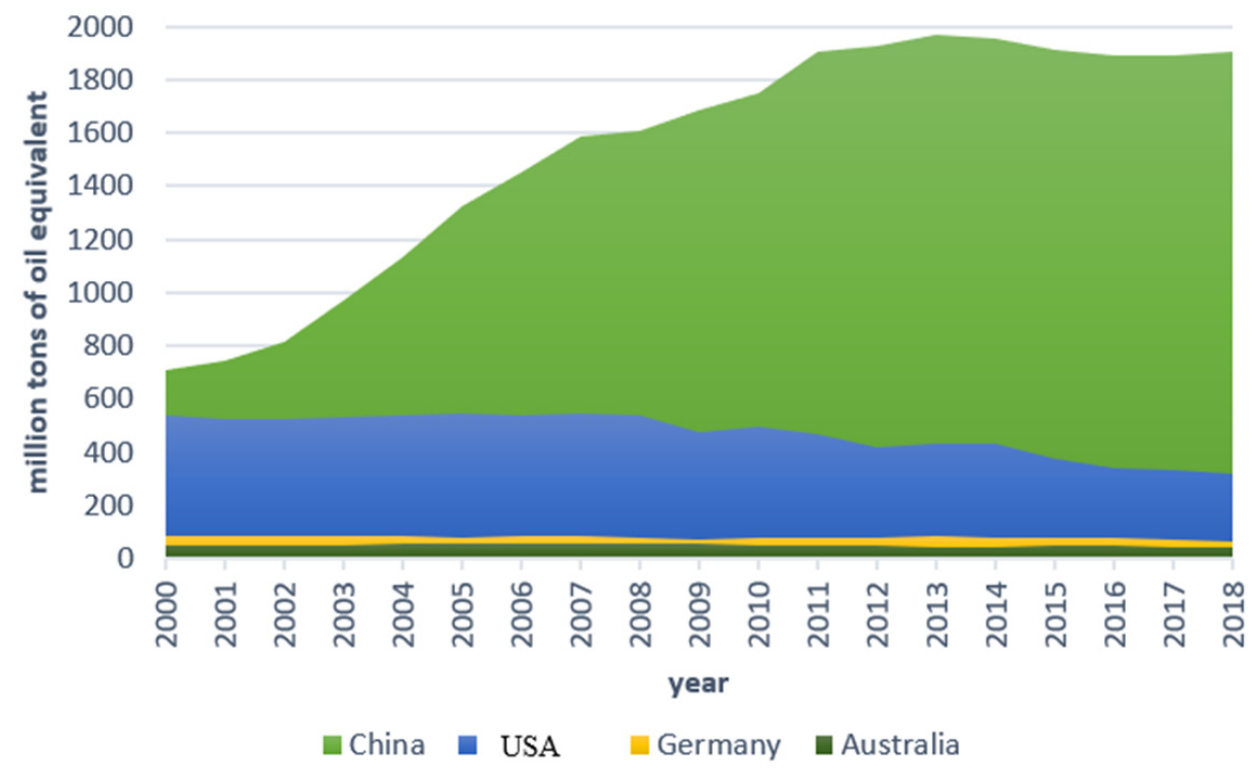

Figure 3. Comparison of coal consumption between China and major countries around the world. Data source: Wind database (https:/ / www.wind.com.cn/, accessed on 15 May 2021).

From the perspective of consumption and utilization efficiency, this study selected industrial coal consumption per capita and industrial coal consumption per unit of GDP as 
the relevant proxy variables to analyze how environmental information disclosure achieved the carbon emissions reduction target. The specific results are shown in Table 5. Columns (1) and (2) show that environmental information disclosure was significantly helpful at reducing the industrial coal consumption per capita, indicating that information disclosure was conducive to promoting the reduction of coal consumption. Columns (3) and (4) show the impact of environmental information disclosure on industrial coal consumption per unit of GDP. It can be seen that environmental information disclosure also significantly reduced the industrial coal consumption per unit of GDP, indicating that information disclosure was conducive to improving the coal utilization efficiency. The calculation of the PITI is based on the emissions of sulfur dioxide and other indicators. Coal consumption is an important factor affecting the emissions of sulfur dioxide in the region. Therefore, with the background of environmental information disclosure, the government was bound to strictly control the regional industrial coal consumption and improve the utilization efficiency of industrial coal to improve the environmental score by promoting the reduction of regional sulfur dioxide emissions. Hypothesis 2 was, therefore, verified.

Table 5. Relationship between environmental information disclosure and coal withdrawal.

\begin{tabular}{|c|c|c|c|c|}
\hline & Percoal & Percoal & Gdpcoal & Gdpcoal \\
\hline & (1) & $(2)$ & (3) & (4) \\
\hline $\mathrm{EIO}$ & $\begin{array}{c}-0.0897^{* * *} \\
(0.0128)\end{array}$ & $\begin{array}{c}-0.0508^{* * *} \\
(0.0157)\end{array}$ & $\begin{array}{c}-0.0624^{* * *} \\
(0.0091)\end{array}$ & $\begin{array}{c}-0.0359 * * * \\
(0.0082)\end{array}$ \\
\hline Control variable & No & Yes & No & Yes \\
\hline Year fixed effect & Yes & Yes & Yes & Yes \\
\hline Region fixed effect & Yes & Yes & Yes & Yes \\
\hline _cons & $\begin{array}{c}10.4497^{* * *} \\
(0.1039)\end{array}$ & $\begin{array}{c}10.2126^{* * *} \\
(0.2480)\end{array}$ & $\begin{array}{c}8.5498 \\
(0.0768)\end{array}$ & $\begin{array}{c}8.4532 * * * \\
(0.1706)\end{array}$ \\
\hline $\mathrm{N}$ & 4010 & 3744 & 4010 & 3744 \\
\hline r2 & 0.9151 & 0.9150 & 0.8420 & 8196 \\
\hline
\end{tabular}

Note: ${ }^{*}, * * * *$ are significant at the level of $10 \%, 5 \%$ and $1 \%$, respectively; In parentheses is the value of robust standard error.

Environmental information disclosure promotes a reduction in coal consumption and an improvement in coal use efficiency. As the main energy causing the increase in carbon emissions, the impact of environmental information disclosure on coal will eventually lead to a change in carbon emissions. The promotion of "coal withdrawal" is the key to reducing carbon emissions. Therefore, it can be considered that the implementation of environmental information disclosure achieved the carbon emissions reduction goal by promoting the process of "coal withdrawal." At present, in the face of high coal consumption, how to better promote the reduction of coal consumption has become the key to solving the problem of carbon emission. The environmental information disclosure makes energy production, which is dominated by coal consumption, subject to external supervision, and the reduction in coal consumption and the improvement of energy utilization efficiency are the inevitable choices to realize the transformation of the energy structure and achieve the carbon emissions reduction targets. From this perspective, promoting environmental information disclosure is effective and necessary.

\section{Discussion}

\subsection{Impact of Clean Energy Development on "Coal Withdrawal" with a Background of Environmental Information Disclosure}

Through the previous analysis, we saw that environmental information disclosure achieved the carbon emissions reduction target by promoting the regional "coal withdrawal" process. Then, how does environmental information disclosure affect the regional "coal withdrawal" process? Coal is the most important energy source for current economic development and social life. The advancement of the "coal withdrawal" process is bound to require the strong substitution of, and be supplemented by, other energy sources to maintain the operation of production and life. Based on this analysis, starting from the 
development of clean energy in each province, regional natural gas consumption and investment in gas infrastructure were selected as relevant proxy variables to measure the development status of clean energy in each region. The impact of clean energy development on regional "coal removal" with a background of environmental information disclosure is further discussed. The specific results are shown in Table 6.

Table 6. Impact of the clean energy development on "coal removal" with the background of environmental information disclosure.

\begin{tabular}{|c|c|c|c|c|c|c|}
\hline & Gas & Gasinfrastructure & Percoal & Gdpcoal & Percoal & Gdpcoal \\
\hline & (1) & (2) & (3) & (4) & (5) & (6) \\
\hline $\mathrm{EIO}$ & $\begin{array}{c}1.8571 \\
(1.4681)\end{array}$ & $\begin{array}{c}0.2397 \\
(0.5191)\end{array}$ & & & & \\
\hline $\mathrm{EIO}^{*}$ gas & & & $\begin{array}{l}-0.0003 \\
(0.0002)\end{array}$ & $\begin{array}{c}-0.0001 \\
(0.0001)\end{array}$ & & \\
\hline gas & & & $\begin{array}{c}-0.0026^{* * *} \\
(0.0006)\end{array}$ & $\begin{array}{c}-0.0015^{* * *} \\
(0.0003)\end{array}$ & & \\
\hline $\begin{array}{c}\mathrm{EIO}^{*} \\
\text { gasinfrastructure }\end{array}$ & & & & & $-0.0026^{* * *}$ & $-0.0012 * * *$ \\
\hline & & & & & $(0.0006)$ & $(0.0003)$ \\
\hline gasinfrastructure & & & & & $\begin{array}{c}0.0034^{* * *} \\
(0.0008)\end{array}$ & $\begin{array}{c}0.0026^{* * *} \\
(0.0007)\end{array}$ \\
\hline Control variable & Yes & Yes & Yes & Yes & Yes & Yes \\
\hline Year fixed effect & Yes & Yes & Yes & Yes & Yes & Yes \\
\hline $\begin{array}{c}\text { Region fixed } \\
\text { effect }\end{array}$ & Yes & Yes & Yes & Yes & Yes & Yes \\
\hline _cons & $\begin{array}{c}49.1088^{* * *} \\
(8.9621)\end{array}$ & $\begin{array}{c}16.2593 * * * \\
(5.0757)\end{array}$ & $\begin{array}{c}10.3137 * * * \\
(0.2736)\end{array}$ & $\begin{array}{c}8.4963 * * * \\
(0.1892)\end{array}$ & $\begin{array}{c}10.1758 * * * \\
(0.2381)\end{array}$ & $\begin{array}{c}8.4369 * * * \\
(0.1673)\end{array}$ \\
\hline $\mathrm{N}$ & 4190 & 4276 & 3658 & 3658 & 3744 & 3744 \\
\hline $\mathrm{r} 2$ & 0.7842 & 0.4468 & 0.9225 & 0.8342 & 0.9163 & 0.8230 \\
\hline
\end{tabular}

Note: ${ }^{* * *},{ }^{* * *}$ are significant at the level of $10 \%, 5 \%$ and $1 \%$, respectively; In parentheses is the value of robust standard error.

Columns ( 1 and 2 ) show that environmental information disclosure improved the regional natural gas consumption and gas infrastructure investment, indicating that environmental information disclosure was conducive to promoting the development of clean energy in the region. Columns (3-6) show the impact of the development of clean energy on regional coal consumption with a background of environmental information disclosure. It can be seen that environmental information disclosure helped to promote the inhibition of clean energy development in coal consumption. That is, the promotion of environmental information disclosure helped to strengthen the "substitution effect" of clean energy on coal consumption.

The implementation of environmental information disclosure could effectively promote the development of clean energy, which showed that the impact of the implementation of this policy on the transformation of the energy structure was effective. Environmental information disclosure involved not only the presentation of the current environmental situation but also the change in the regional development model caused by the implementation of this policy, especially the promotion of changes in the environmental field. The impact of the environmental information disclosure policy on the change to the regional production model was an important factor that affected the sustainable development of a region. Through this research, it was shown that this policy could indeed play a positive role regarding information disclosure and promote the development of regional clean energy to promote the realization of the regional green development model. In this context, the development potential of energy structure transformation could be released, which was conducive to accelerating the transformation of the regional energy structure. China's current coal consumption is still large, which puts great pressure on promoting the process of carbon emissions reduction. To achieve peak carbon dioxide emissions and carbon neutralization, this policy will accelerate the reduction of coal consumption and cause China's economic development to eliminate its dependence on coal. With this background, there is an inevitable trend toward promoting the development of clean energy and the 
transformation of the energy structure. As an important agent that is leading the way in energy development, the government's guidance and attention to the development of clean energy are very important.

Environmental information disclosure had a weak effect on carbon emissions reduction by promoting the development of renewable energy. It can be seen that the positive impact of renewable energy needs to be improved. The development of renewable energy in China started late, but the development speed was very fast. By 2019, the consumption of renewable energy in China was only lower than that of the EU compared with other major countries, which reflects the broad prospects of China's renewable energy consumption (as shown in Figure 4). Corresponding to the greater consumption demand, the production capacity of renewable energy in China currently has a lot of room for improvement. Compared with the development of global renewable energy production capacity, there is a large gap between China and the world in this field, and China also lags behind the world in terms of development speed, which not only leads to the expansion of the gap between China and the world in this field but also directly affects the domestic demand for renewable energy consumption (as shown in Figure 5). The development of renewable energy in China still has great potential.

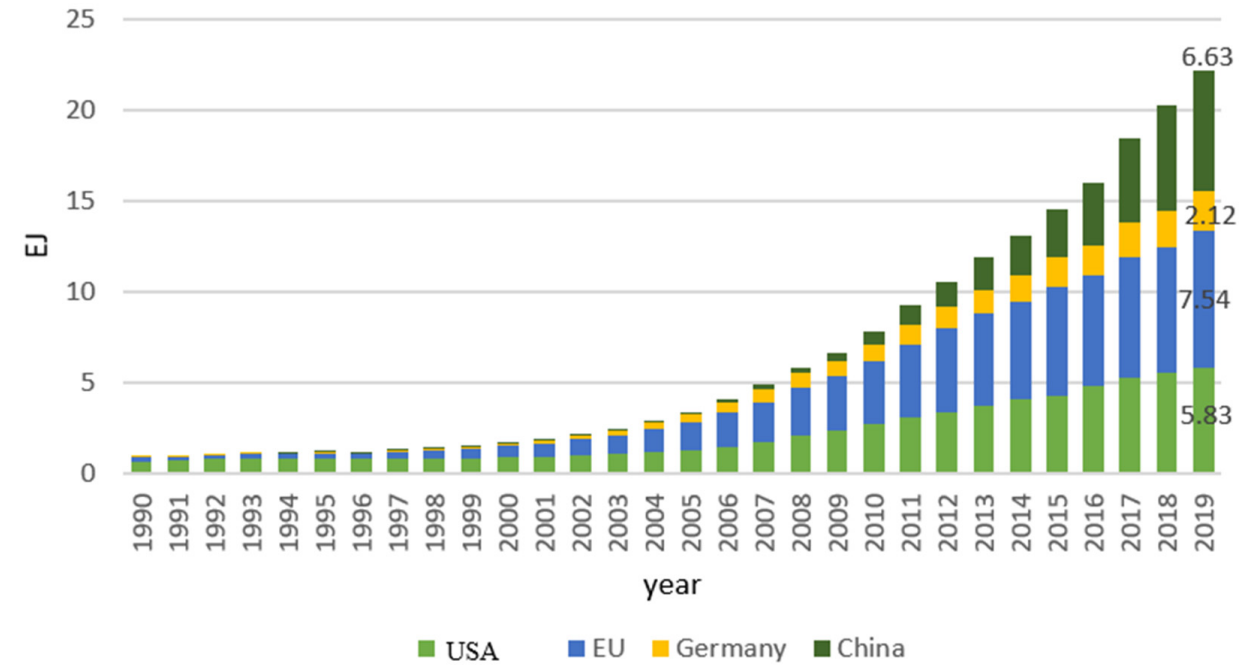

Figure 4. Comparison of renewable energy consumption between China and other major regions. Data source: Wind database (https:/ / www.wind.com.cn/, accessed on 15 May 2021).

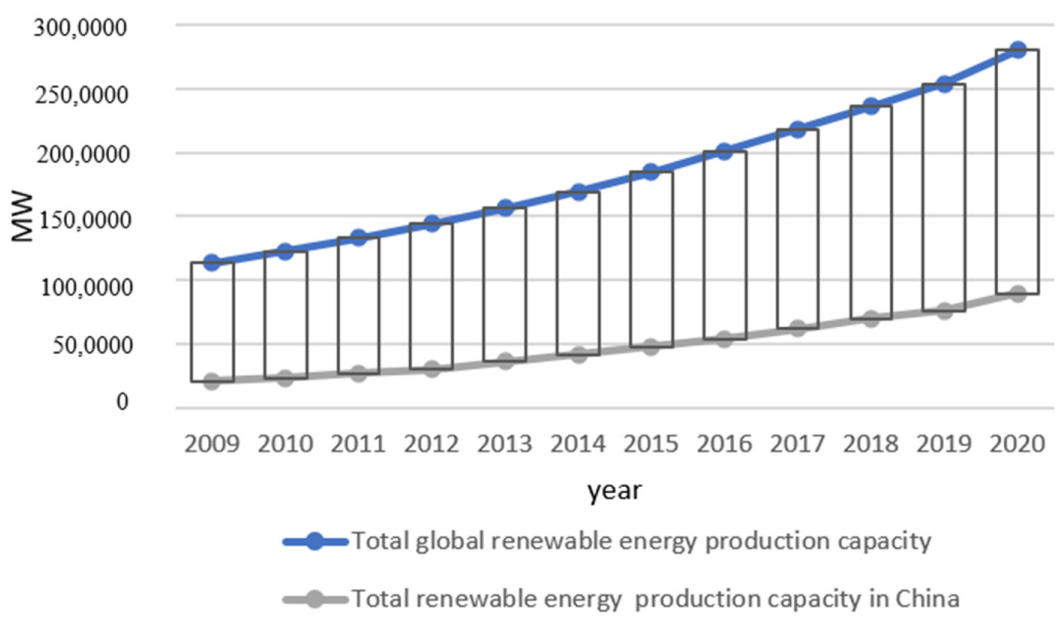

Figure 5. Comparison of renewable energy production capacity between China and the world. Data source: Wind database (https:/ /www.wind.com.cn/, accessed on 15 May 2021). 
In addition, the regional support for renewable energy development will also directly affect its development level. Therefore, this study organized the government's financial expenditure on renewable energy development in Eastern, Central, Western, and Northeastern China and compared their expenditures with the regional industrial coal consumptions. This was conducted to explore the importance of renewable energy development in different regions and to understand the relationship between it and regional coal consumption changes. Since there was incomplete data for fiscal expenditure on renewable energy, the information may be incomplete regarding the summation of provincial data. This study selected, as much as possible, provinces with more complete data for regional aggregate reporting. Thus, the present situation in the four regions could not fully represent the overall situation of the region and could not be compared between regions. This part of the study focused on the relationship between the degree of financial support for renewable energy and the trend of regional coal consumption (as shown in Figure 6).

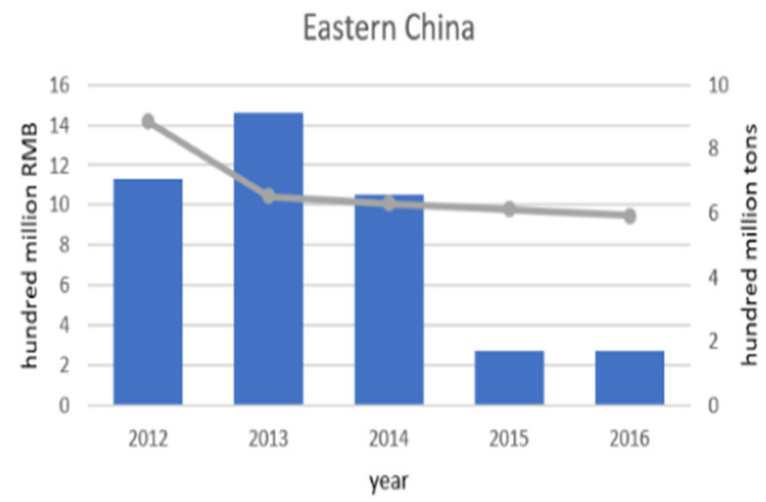

Fiscal expenditure on renewable energy $\quad \rightarrow$ Industrial coal consumption Western China

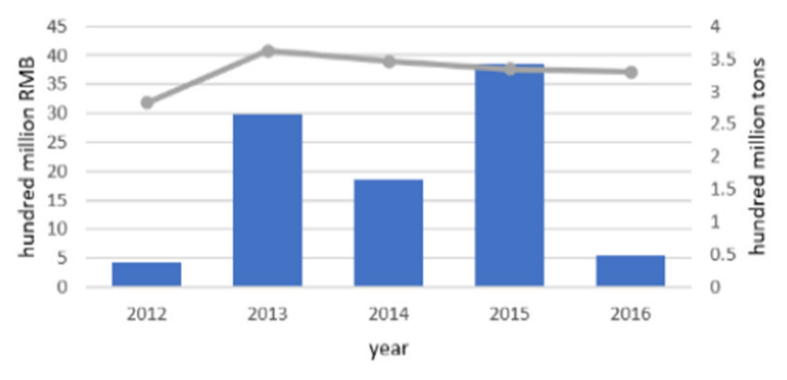

Fiscal expenditure on renewable energy $\rightarrow$ Industrial coal consumption
Central China

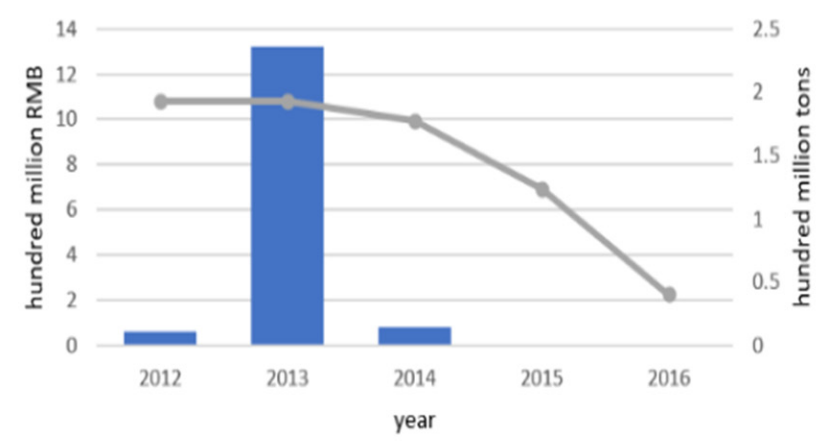

Fiscal expenditure on renewable energy $\quad \rightarrow$ Industrial coal consumption Northeastern China

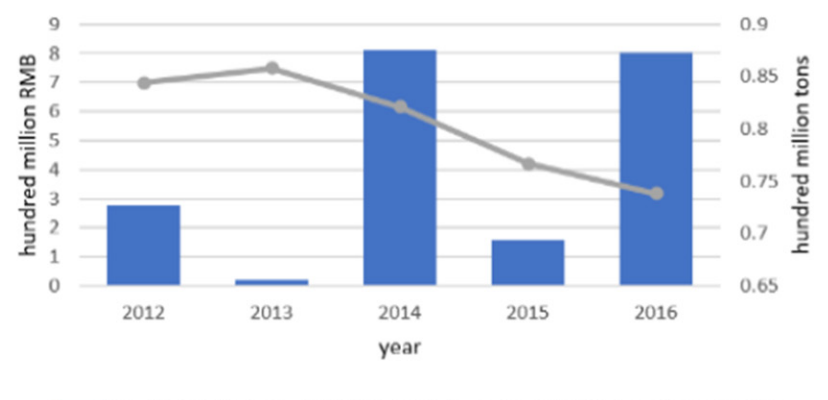

Fiscal expenditure on renewable energy $\rightarrow$ Industrial coal consumption

Figure 6. Trend comparison of fiscal expenditure on renewable energy and industrial coal consumption in four major regions of China. Data source: Wind database (https:/ / www.wind.com.cn/, accessed on 15 May 2021).

It can be seen that the financial support for renewable energy in Northeastern China showed a fluctuating upward trend and had a positive relationship with the decline of regional industrial coal consumption, but there was no positive relationship between the financial support for renewable energy and the decline of industrial coal consumption in other regions. It can therefore be inferred that the decline in industrial coal consumption was driven by other factors, which is also consistent with the empirical test results in Table 6. This shows that the current financial support for renewable energy in China needs to be further improved.

\subsection{Analysis on the Strengthening Impact of Public Environmental Supervision on Carbon} Emission Reduction Due to Environmental Information Disclosure

As an external constraint that promotes environmental quality improvement, the strengthening impact of public environmental supervision on carbon emissions reduc- 
tion caused by environmental information disclosure is also worth further discussion. The improvement of environmental quality not only needs government intervention and enterprise action, but also public participation in environmental protection since it is an important force that promotes change in the whole social environment. As the government's response to public participation in environmental protection will affect the enthusiasm of public participation, this study combined public participation in environmental protection with the government's response, selected the number of letters from the public to the environment and the government's treatment to reflect the public's concern about environmental protection, and used this variable to interact with the environmental information disclosure variable during model testing. The specific results are shown in Table 7.

Table 7. Analysis on the strengthening impact of public environmental supervision on carbon emissions reduction due to environmental information disclosure.

\begin{tabular}{|c|c|c|c|c|c|c|}
\hline & totalCO $\mathrm{CO}_{2}$ & totalCO $\mathrm{CO}_{2}$ & perCO $_{2}$ & perCO $_{2}$ & $\mathrm{gdpCO}_{2}$ & $\operatorname{gdpCO}{ }_{2}$ \\
\hline & (1) & $(2)$ & (3) & (4) & (5) & (6) \\
\hline EIO * letter & $\begin{array}{c}-0.1649 * * * \\
(0.0247)\end{array}$ & $\begin{array}{c}-0.1159^{* * *} \\
(0.0299)\end{array}$ & $\begin{array}{c}-0.1719 * * * \\
(0.0256)\end{array}$ & $\begin{array}{c}-0.1265^{* * *} \\
(0.0317)\end{array}$ & $\begin{array}{c}-0.1499 * * * \\
(0.0259)\end{array}$ & $-0.0629 *$ \\
\hline letter & $\begin{array}{l}-0.1112 \\
(0.0703)\end{array}$ & $\begin{array}{l}-0.0572 \\
(0.0364)\end{array}$ & $\begin{array}{l}-0.0924 \\
(0.0756)\end{array}$ & $\begin{array}{l}-0.0345 \\
(0.0424)\end{array}$ & $\begin{array}{l}-0.0709 \\
(0.0849)\end{array}$ & $\begin{array}{l}-0.0133 \\
(0.0363)\end{array}$ \\
\hline $\begin{array}{l}\text { Control } \\
\text { variable }\end{array}$ & No & Yes & No & Yes & No & Yes \\
\hline Year fixed effect & Yes & Yes & Yes & Yes & Yes & Yes \\
\hline $\begin{array}{c}\text { Region fixed } \\
\text { effect }\end{array}$ & Yes & Yes & Yes & Yes & Yes & Yes \\
\hline _cons & $\begin{array}{c}17.5705^{* * *} \\
(0.0829)\end{array}$ & $\begin{array}{c}17.2813^{* * *} \\
(0.2133)\end{array}$ & $\begin{array}{c}10.4489 * * * \\
(0.0876)\end{array}$ & $\begin{array}{c}10.1548^{* * *} \\
(0.2004)\end{array}$ & $\begin{array}{c}8.4755^{* * *} \\
(0.1004)\end{array}$ & $\begin{array}{c}8.4973^{* * * *} \\
(0.2379)\end{array}$ \\
\hline $\mathrm{N}$ & 2555 & 2386 & 2555 & 2386 & 2503 & 2386 \\
\hline $\mathrm{r} 2$ & 0.8860 & 0.9132 & 0.8876 & 0.9140 & 0.7886 & 0.8352 \\
\hline
\end{tabular}

Note: ${ }^{* * *}, * * *$ are significant at the level of $10 \%, 5 \%$ and $1 \%$, respectively; In parentheses is the value of robust standard error.

It can be seen that the improvement to public environmental protection supervision helped to strengthen the positive impact of environmental information disclosure in regional carbon emissions reduction, and the results passed the significance level test, indicating that promoting regional carbon emission reduction requires not only the participation of the government and enterprises but also improvements of the degree of public concern and participation in the environment. As such, Hypothesis 3 was verified.

Expanding the main body of environmental protection supervision, mobilizing the public's enthusiasm for environmental protection supervision, and forming a situation of attaching great importance to regional environmental protection in the whole society is conducive to the timely correction of the government's sub-optimal decision-making and restricts the negative external impact of enterprises on the environment. Regarding the third-party public as an independent supervision subject and bringing the public into environmental protection can effectively reduce the interference from subjects that directly affect economic development regarding environmental supervision and maintain the independence of supervision. At the same time, as a basic part of society, the public participates in all aspects of social development, and its external supervision has a wider scope and strong effectiveness for a given period. Therefore, improving the public's enthusiasm for environmental supervision plays a supporting role in improving the external supervision system and improving the effectiveness of environmental protection.

As the improvement of public participation in environmental protection helps to accelerate the improvement of the regional environment, the current situation of public participation in environmental protection in various regions of China was also statistically analyzed in this study (as shown in Figure 7). In general, the degree of public participation in environmental protection was higher in eastern and central China, while the degree of public participation in western China was the lowest. In addition, China's informatization 
began to develop rapidly in 2011. The popularization and improvement of telephones and networks provided more channels and platforms for the public to voice their opinions on environmental protection. After 2011, the decline in the number of environmental protection letters in various regions was due to the emergence of more channels for public participation. With this background, it can be seen that public participation in environmental protection was still higher in the central and eastern regions after 2011. Therefore, the western and northeastern regions need to increase efforts to improve their enthusiasm for public participation in environmental protection.

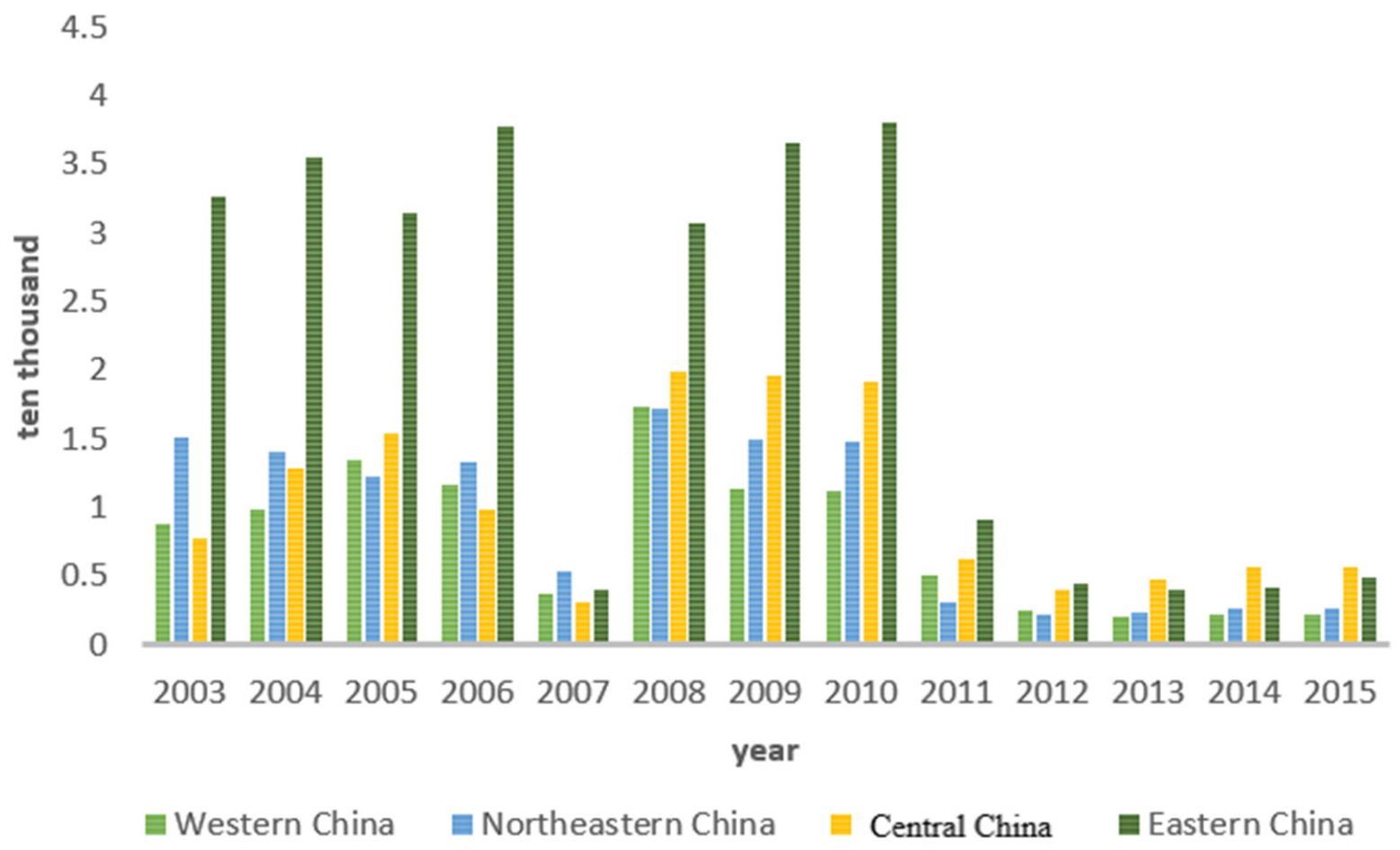

Figure 7. Comparison of the average quantity of environmental protection letters in four regions of China. Data source: China Environment Yearbook (https:/ / data.cnki.net/, accessed on 15 May 2021).

\section{Conclusions}

Starting from prefecture-level cities in China, this study considered the implementation of environmental information disclosure policy as a "quasi-natural experiment" and identified the "net effect" of environmental information disclosure on regional carbon emissions reduction by constructing a DID model. Throughout the research, it was found that the promotion of the environmental information disclosure process could significantly reduce regional carbon emissions, where this result had a better impact on China's central and western regions and low carbon emissions density areas, which provides environmental policy support for accelerating the transformation of the economic development model in economically backward areas, and reflects the effectiveness of this method for carbon emissions constraints. With the promotion of information disclosure, the realization of carbon emissions reduction target was mainly achieved through the effective inhibition of coal consumption by the former, that is, the promotion of the "coal withdrawal" process, which reduced the regional carbon emissions level. From the economic level, it provided a development space for China's clean energy development and the transformation of the energy structure. In addition, environmental information disclosure accelerated the process of the substitution of clean energy for coal and strengthened the positive impact of external public supervision regarding reducing carbon emissions. It can be seen that the implementation of this policy promoted the development of new energy, which was the key to the realization of "coal withdrawal." The beneficial role of environmental information 
disclosure and the necessity of clean energy development were also supported. At the same time, the policy also effectively improved the public's enthusiasm for participating in carbon emissions reductions, and the increase in the number of participants provided a favorable external environment for improving the awareness of carbon emission reduction in the whole society.

This study aimed to explore the potential feasible ways to promote the transformation of China's energy structure and reduce carbon emissions to promote the realization of China's carbon neutral and low-carbon cycle development model as soon as possible. The main conclusions are as follows.

First, whether at the prefecture-level or the provincial level, environmental information disclosure could effectively reduce regional carbon emissions, where this result had a better impact on the central and western regions and regions with low carbon emissions densities. The implementation of the information disclosure policy expanded the ways that the public could obtain information and improved the flow of information. This policy played a positive supporting role in strengthening environmental supervision and restricting the behavior of regional economic subjects. At present, environmental information disclosure involves 113 cities in China. By promoting the flow of information, the policy effectively achieved the carbon emissions reduction target, reflecting the necessity of implementing the policy. Therefore, environmental information disclosure should be promoted in all cities, especially in the central and western regions and low-carbon emissions regions. At the same time, for the eastern and high carbon emissions areas, the implementation intensity or policy model should be adjusted in combination with the characteristics of regional economic development to provide space for the policy to have a positive effect. In short, it is necessary to promote environmental information disclosure further and improve the content and policy implementation model, which will be the focus in the future.

Second, the realization of the positive effect of carbon emissions reduction was mainly attributed to the environmental information disclosure, which promoted the reduction of regional coal consumption and the improvement of coal utilization efficiency. Coal is the main energy source that causes an increase in carbon emissions. The control of coal consumption can fundamentally inhibit carbon emissions. Environmental information disclosure effectively restricts coal consumption, which provides space for the development of clean energy and a reduction in carbon emissions. Based on the effective impact of environmental information disclosure on coal withdrawal, the government should pay more attention to the impact of information flow on energy transformation, increase policy support for possibly conducive ways to withdraw coal, and expand the selection range of energy indicators for information disclosure to increase the impact of information disclosure on regional energy consumption and to improve the transformation space of the regional energy structure.

Third, clean energy is an important factor that affects the positive effect of environmental information disclosure on "coal withdrawal." In addition, the improvement of public environmental supervision helped to strengthen the positive impact of environmental information disclosure on carbon emissions reduction. From the regional perspective, public participation in environmental protection in the western and northeastern regions needs to be further improved. The realization of "coal withdrawal" is bound to require the effective substitution of other energy resources to meet the normal operation needs of the social economy. As the first choice for the transformation and development of the energy structure, the vigorous development of clean energy in the background of environmental information disclosure plays a positive role by squeezing the coal market share. Therefore, in the process of promoting the transformation of the energy structure, it is necessary for the government to increase policy guidance for the development of clean energy in the whole society and give financial support and policy preferences to accelerate the substitution of clean energy for coal consumption. At the same time, improvements should be made to publicize environmental protection and to guide the public to participate in environmental supervision in various ways to improve the public's overall awareness of environmental 
protection and increase their enthusiasm for external supervision, especially the promotion of public awareness of environmental protection participation in the western region and northeastern region of China. This study provides strong support for further promoting China's environmental information disclosure and provides a reference for the realization of China's carbon emissions reduction goals, in addition to the exploration of diversified paths for low-carbon sustainable development.

Author Contributions: Conceptualization: N.L. and B.S.; methodology: N.L. and B.S.; data curation: R.K.; formal analysis: N.L., B.S. and R.K.; visualization: R.K.; writing-original draft: N.L., B.S. and R.K.; writing-review and editing: N.L. All authors have read and agreed to the published version of the manuscript.

Funding: This research is funded by the Youth Project of National Natural Science Foundation of China (No. 72103163), Shaanxi Provincial Natural Science Basic Research Program (No. 2021JQ-457), China-Central Eastern European Countries Higher Joint Education Project (No. 202028). This research is also supported by Shaanxi Key Laboratory for Carbon Neutral Technology.

Institutional Review Board Statement: Not applicable.

Informed Consent Statement: Not applicable.

Data Availability Statement: Publicly available datasets were analyzed in this study. This data can be found here: http:/ / www.stats.gov.cn/; https:/ / data.cnki.net/ (accessed on 25 August 2021).

Conflicts of Interest: The authors declare no conflict of interest.

\section{References}

1. Farooq, M.U.; Shahzad, U.; Sarwar, S.; Li, Z.J. The impact of carbon emission and.forest activities on health outcomes: Empirical evidence from China. Environ. Sci. Pollut. Res. 2019, 26, 12894-12906. [CrossRef] [PubMed]

2. Pour, S.H.; Wahab, A.; Shahid, S.; Asaduzzaman, M.; Dewan, A. Low impact development techniques to mitigate the impacts of climate-change-induced urban floods: Current trends, issues and challenges. Sustain. Cities Soc. 2020, 62, 102373. [CrossRef]

3. Sun, Y.; Qian, L.; Chen, T.; Jia, X. Dynamic factor analysis of trends in temporal-spatial patterns of China's coal consumption. Sustainability 2015, 7, 15119-15135. [CrossRef]

4. Tang, X.; Jin, Y.; Mclellan, B.C.; Wang, J.; Li, S. China's coal consumption declining-Impermanent or permanent? Resour. Conserv. Recycl. 2016, 129, 307-3013. [CrossRef]

5. Dialga, I. Evaluating Normandy's sustainable development and energy transition policies. J. Clean. Prod. 2021, $305,127096$. [CrossRef]

6. Falcone, P.M. Analysing stakeholders' perspectives towards a socio-technical change: The energy transition journey in Gela Municipality. AIMS Energy 2018, 6, 645-657. [CrossRef]

7. Hfer, T.; Madlener, R. A participatory stakeholder process for evaluating sustainable energy transition Scenarios. Energy Policy 2020, 139, 111277. [CrossRef]

8. Bengart, P.; Vogt, B. Fuel mix disclosure in Germany-The effect of more transparent information on consumer preferences for renewable energy. Energy Policy 2021, 150, 112120. [CrossRef]

9. Wang, Y.; Zhao, H. The impact of China's carbon trading market on regional carbon emission efficiency. China Popul. Resour. Environ. 2019, 29, 50-58.

10. Liu, C.M.; Sun, Z.; Zhang, J. Research on the effect of carbon emission reduction policy of China's carbon emission trading pilot. China Popul. Resour. Environ. 2019, 29, 49-58.

11. Yu, X.Y.; Dong, Z.J.; Zhou, D.Q.; Sang, X.Z.; Chang, C.T.; Huang, X.H. Integration of tradable green certificates trading and carbon emissions trading: How will Chinese power industry do? J. Clean. Prod. 2020, 279, 123485. [CrossRef]

12. Qi, S.; Cheng, S.; Cui, J. Environmental and economic effects of China's carbon market pilots: Empirical evidence based on a DID mode. J. Clean. Prod. 2020, 279, 123720. [CrossRef]

13. Liu, W.J.; Liu, T.T.; Li, Y.Y.; Liu, M. Recycling carbon tax under different energy efficiency improvements: A CGE analysis of China. Sustainability 2021, 13, 4804. [CrossRef]

14. Lou, F. A simulation study on the effect of carbon tax collection on China's macro economy and carbon emission reduction. J. Quant. Tech. Econ. 2014, 31, 84-96.

15. Zhang, J.J.; Ding, L.L.; Sun, L.C. Research on carbon emission decision of enterprises considering the substitution effect of carbon tax and carbon trading. China Popul. Resour. Environ. 2019, 29, 41-48.

16. Zhou, B.; Zhang, C.; Song, H.Y.; Wang, Q.W. How does emission trading reduce China's carbon intensity? An exploration using a decomposition and difference-in-differences approach. Sci. Total. Environ. 2019, 676, 514-523. [CrossRef]

17. Wang, L.; Liu, C.; Yang, X. Research on carbon emission reduction effect of China's carbon trading pilot. Adv. Soc. Sci. Res. J. 2020, 7, 240-250. [CrossRef] 
18. Zhang, H.; Zhang, B. The unintended impact of carbon trading of China's power sector. Energy Policy 2020, 147, 111876. [CrossRef]

19. Yg, A.; Meng, L.A.; Jxbcd, E.; Yu, L.F. Evaluation of effectiveness of China's carbon emissions trading scheme in carbon mitigation. Energy Econ. 2020, 90, 104872. [CrossRef]

20. Liu, X.F.; Zhou, X.X.; Zhu, B.Z.; Wang, P. Measuring the efficiency of China's carbon market: A comparison between efficient and fractal market hypotheses. J. Clean. Prod. 2020, 271, 122885. [CrossRef]

21. Li, F.; Wang, W.J. Comparative study on quota allocation methods of pilot carbon market in China. Res. Econ. Manag. 2015, $36,9-15$.

22. Liao, Z.L.; Zhu, X.L.; Shi, J.R. Case study on initial allocation of Shanghai carbon emission trading based on Shapley value. J. Clean. Prod. 2015, 103, 338-344. [CrossRef]

23. Qi, S.Z.; Wang, B.B. Transaction initial quota allocation: A comparative analysis of models and methods. Wuhan Univ. J. Philos. Soc. Sci. 2013, 66, 19-28.

24. Sun, S.; Zhou, C. Operation mechanism and evaluation of carbon market in electricity industry: A review of its current status and future perspectives. IOP Conf. Ser. Earth Environ. Sci. 2019, 300, 042063. [CrossRef]

25. Sun, F.B.; Li, X.F. Comparison and reference of carbon emission trading market mechanism. J. Henan Univ. Sci. Technol. Soc. Sci. 2010, 28, 91-95.

26. Wettestad, J.; Jevnaker, T. Smokescreen politics? Ratcheting up EU emissions trading in 2017. Rev. Policy Res. 2019, 36, 635-659. [CrossRef]

27. Lee, Y.J.; Kim, N.W.; Choi, K.H.; Yoon, S.M. Analysis of the informational efficiency of the EU carbon emission trading market: Asymmetric MF-DFA approach. Energies 2020, 13, 2171. [CrossRef]

28. Dai, X.; Xiao, L.; Wang, Q.; Dhesi, G. Multiscale interplay of higher-order moments between the carbon and energy markets during phase iii of the EU-ETS. Energy Policy 2021, 156, 112428. [CrossRef]

29. Xiong, L.; Qi, S.Z. Structural defects, institutional reform and its impact of EU carbon emission trading system. Chin. J. Eur. Stud. 2012, 30, 51-64.

30. Liu, M.M. On the initial allocation of greenhouse gas emission quotas. J. Int. Trade 2012, 8, 121-127.

31. Cong, R.G.; Wei, Y.M. Experimental comparison of impact of auction format on carbon allowance market. Renew. Sustain. Energy Rev. 2012, 16, 4148-4156. [CrossRef]

32. Wang, Q.; Wu, S.T. Carbon trading thickness and market efficiency in a socialist market economy. Chin. J. Popul. Resour. Environ. 2018, 16, 17-27. [CrossRef]

33. Lin, B.Q.; Jia, Z.J. Why do we suggest small sectoral coverage in China's carbon trading market? J. Clean. Prod. 2020, $257,120557$. [CrossRef]

34. Qu, X.S.; Deng, X.; Yu, Z.N. Global carbon emissions trading and its efficiency: An Empirical Analysis Based on a Dynamic CGE model. Financ. Econ. 2017, 4, 99-107.

35. Martin, R.; Muuls, M.; Wagner, U.J. The impact of the European Union emissions trading scheme on regulated firms: What is the evidence after ten years? Rev. Environ. Econ. Policy 2016, 10, 129-148. [CrossRef]

36. Li, H.; Peng, W. Carbon tax, subsidy, and emission reduction: Analysis based on DSGE model. Complexity 2020, 6, 1-10.

37. Liu, X.; Leung, Y.; Xu, Y.; Linda, C.; Wing, Y. The effect of carbon tax on carbon emission abatement and GDP: A case study. J. Geogr. Syst. 2017, 19, 399-414. [CrossRef]

38. Meng, S.; Siriwardana, M.; Mcneill, J. The environmental and economic impact of the carbon tax in Australia. Environ. Resour. Econ. 2013, 54, 313-332. [CrossRef]

39. Hu, H.; Zhou, W. The impact of carbon tax policy on the carbon emission reduction and profit. Int. J. Smart Home 2014, 8, 175-184. [CrossRef]

40. Zou, F.; Zhou, Y.; Yuan, C. The impact of retailers' low-carbon investment on the supply chain under carbon tax and carbon trading policies. Sustainability 2020, 12, 3597. [CrossRef]

41. Arasto, A.; Tsupari, E.; Karki, J.; Sormunen, R.; Korpinen, T.; Hujanen, S. Feasibility of significant CO2 emission reductions in thermal power plants-Comparison of biomass and CCS. Energy Procedia 2014, 63, 6745-6755. [CrossRef]

42. Shuai, Z.A.; Yu, Z.; Ran, T.A.; Ll, A.; Lei, Z.A.; Jian, D.A. Multi-objective optimization for the deployment of Carbon Capture Utilization and Storage supply Chain considering economic and environmental performance. J. Clean. Prod. 2020, $270,122481$.

43. Shi, M.J.; Zhou, S.M. The role of low carbon technology development in China's realization of emission reduction targets. Manag. Rev. 2010, 22, 48-53.

44. Razzaq, A.; Sharif, A.; Ahmad, P.; Jermsittiparsert, K. Asymmetric role of tourism development and technology innovation on carbon dioxide emission reduction in the Chinese economy: Fresh insights from QARDL approach. Sustain. Dev. 2020, $28,1-27$. [CrossRef]

45. Chen, W.Y.; Wu, Z.X.; Wang, W.Z. Carbon capture and storage (CCS) and its potential role to mitigate carbon emission in China. Environ. Sci. 2007, 28, 1178-1182.

46. Craig, M.T.; Jaramillo, P.; Zhai, H.; Klima, K. The Economic merits of flexible Carbon Capture and sequestration as a compliance strategy with the clean power plan. Environ. Sci. Technol. 2017, 51, 1102-1109. [CrossRef]

47. Duan, H. The public perspective of carbon capture and storage for CO2 emission reductions in China. Energy Policy 2010, 38 , 5281-5289. [CrossRef] 
48. Zhang, X.; Fan, J.L.; Wei, Y.M. Technology roadmap study on carbon capture, utilization and storage in China. Energy Policy 2013, 59, 536-550. [CrossRef]

49. Zhou, F.; Li, L.S. Analysis on the effect of technological innovation diffusion based on the carbon emission reduction. Manag. Eng. 2014, 16, 96-100.

50. Shi, M.; Zhou, S. The impact of low carbon technology development on China's CO2 emission reduction. Manag. Rev. 2010, $22,48-53$.

51. Luo, M. The effectiveness of carbon emission reduction demands for sustainable development based on low-carbon technology. Agro Food Ind. Hi-Tech 2017, 28, 3474-3477.

52. Feng, Y.; Chen, H.; Chen, Z.J.; Wang, Y.N.; Wei, W.D. Has environmental information disclosure eased the economic inhibition of air pollution? J. Clean. Prod. 2021, 284, 125412. [CrossRef]

53. Lin, Y.T.; Huang, R.T.; Yao, X. Air pollution and environmental information disclosure: An empirical study based on heavy polluting industries. J. Clean. Prod. 2021, 278, 124313. [CrossRef]

54. Zhong, S.; Li, J.; Zhao, R. Does environmental information disclosure promote sulfur dioxide (SO2) remove? New evidence from 113 cities in China. J. Clean. Prod. 2021, 5, 126906. [CrossRef]

55. Stavins, R.N. Regulating pollution through information disclosure: Facility response to the toxics release inventory. Reprod. Toxicol. 2015, 58, 210-220.

56. Pan, D.; Fan, W.C. Benefits of environmental information disclosure in managing water pollution: Evidence from a quasi-natural experiment in China. Environ. Sci. Pollut. Res. 2021, 28, 1-18. [CrossRef]

57. Tan, J.; Eguavoen, I. Digital environmental governance in China: Information disclosure, pollution control, and environmental activism in the Yellow River Delta. Water Altern. 2017, 10, 910-929.

58. Wang, X.; Guo, H.; Hao, L.; Li, X. Study on the system and practice of water environment information disclosure in China. Environ. Sustain. Dev. 2018, 43, 84-88.

59. Tang, Y.; Xin, M.; Zang, H.; Gao, Y. Information disclosure on hazards from industrial water pollution incidents: Latent resistance and countermeasures in China. Sustainability 2018, 10, 1475. [CrossRef]

60. Sun, Z.W.; Luo, D.L.; Zheng, S.Q.; Wan, G.H. Environmental assessment, promotion of local officials and environmental governance: Based on empirical evidence from 86 key cities in China from 2004 to 2009. J. Tsinghua Univ. Philos. Soc. Sci. 2014, $29,49-62$.

61. Zhang, J.; Fan, H.C.; Xu, Z.W.; Zhou, L.F. The structural reduction of GDP growth: From the perspective of official assessment mechanism. Econ. Res. J. 2020, 55, 31-48.

62. Wagenet, L.P.; Pfeffer, M.J. Organizing citizen engagement for democratic environmental planning. Soc. Nat. Resour. 2007, 20, 801-813.

63. Intergovernmental Panel on Climate Change (IPCC). Climate Change 2007; The Fourth Assessment Report of the Intergovernmental Panel on Climate Change; Cambridge University Press: Cambridge, UK, 2007.

64. Ma, S.G. Impact of sulfur tax on sulfur dioxide emission and energy consumption in China. China Ind. Econ. 2008, 2, 20-30.

65. Jiang, W.L.; Martek, I. Political risk analysis of foreign direct investment into the energy sector of developing countries. J. Clean. Prod. 2021, 302, 127023.

66. Wang, Y.B.; Lu, Y. Fiscal decentralization, environmental regulation and regional environmental quality: An empirical analysis based on dynamic panel model. Inq. Econ. Issues 2021, 3, 120-137.

67. Bertrand, M.; Mullainathan, D.S. How much should we trust differences-in-differences estimates? Q. J. Econ. 2004, 119, $249-275$.

68. Meyer, B. Natural and quasi-natural experiments in economics. J. Bus. Econ. Stat. 1995, 13, 151-162.

69. Han, F.; Xie, R. Does producer services agglomeration reduce carbon emissions-Spatial econometric analysis of panel data of cities at prefecture level and above in China. J. Quant. Tech. Econ. 2017, 34, 40-58.

70. Shi, B.B.; Wu, L.; Kang, R. Clean development, energy substitution, and carbon emissions: Evidence from Clean Development Mechanism (CDM) project implementation in China. Sustainability 2021, 13, 860. [CrossRef]

71. Alam, M.M.; Murad, M.W.; Nornanc, A.H.M.; Ozturk, I. Relationships among carbon emissions, economic growth, energy consumption and population growth: Testing environmental Kuznets curve hypothesis for Brazil, China, India and Indonesia. Ecol. Indic. 2016, 70, 466-479.

72. Hu, B.; Li, Z.T.; Zhang, L. Long-run dynamics of sulphur dioxide emissions, economic growth, and energy efficiency in China. J. Clean. Prod. 2019, 227, 942-949. [CrossRef]

73. Jiang, J.J.; Ye, B.; Zhou, N.; Zhang, X.L. Decoupling analysis and environmental Kuznets curve modelling of provincial-level $\mathrm{CO}_{2}$ emissions and economic growth in China: A case study. J. Clean. Prod. 2019, 212, 1242-1255. [CrossRef]

74. Song, Y.; Sun, J.J.; Zhang, M.; Su, B. Using the Tapio-Z decoupling model to evaluate the decoupling status of $\mathrm{China}^{\prime} \mathrm{CO} \mathrm{CO}_{2}$ emissions at provincial level and its dynamic trend. Struct. Chang. Econ. Dyn. 2020, 52, 120-129. [CrossRef] 